\author{
Federal Reserve Bank of Dallas \\ Globalization and Monetary Policy Institute \\ Working Paper No. 134 \\ http://www.dallasfed.org/assets/documents/institute/wpapers/2012/0134.pdf
}

\title{
The Effect of Commodity Price Shocks on Underlying Inflation: The Role of Central Bank Credibility ${ }^{*}$
}

\author{
J. Scott Davis \\ Federal Reserve Bank of Dallas
}

December 2012

\begin{abstract}
This paper seeks to document and explain the effect of a commodity price shock on underlying core inflation, and how that effect changes both across time and across countries. Impulse responses derived from a structural VAR model show that across many countries there was a break in the response of core inflation to a commodity price shock. In an earlier period, a shock to commodity prices would lead to a large and significant increase in core inflation, but in later periods, the effect was insignificant. To explain this, we construct a large-scale DSGE model with both headline and core inflation, and most significantly, a mechanism whereby fluctuations in inflation caused by purely transitory shocks can become incorporated into long-term inflation expectations. Inflation has a trend and a cyclical component. Private agents cannot distinguish between the two, so a cyclical fluctuation in inflation may be confused for a shift in the trend component. Bayesian estimation reveals that there was a change between the earlier and the later periods in the parameter that governs the anchoring of expectations. Impulse responses derived from simulations of the model show that this change in the effect of commodity prices on core inflation is driven by the change in the anchoring of inflation expectations.
\end{abstract}

JEL codes: C11; E31; E50

\footnotetext{
* Scott Davis, Research Department, Federal Reserve Bank of Dallas, 2200 N. Pearl Street, Dallas, TX 75201. 214-922-5124. scott.davis@dal.frb.org. This paper was begun while the author was a Research Fellow at the Hong Kong Institute for Monetary Research during the summer of 2012. I would like to thank Dong He for inviting me to Hong Kong, and I would like to thank the researchers and staff at the HKIMR and the Hong Kong Monetary Authority, in particular Wei Liao, Hongyi Chen, Honglin Wang, Tommy Wu, Ka-Fai Li, and Wenqi Liu. I would also like to thank Mick Devereux, Roger Farmer, and James Yetman for many helpful comments, suggestions, and conversations, and Payton Odom for excellent research assistance. The views in this paper are those of the author and do not necessarily reflect the views of the Hong Kong Institute for Monetary Research, the Federal Reserve Bank of Dallas or the Federal Reserve System.
} 


\section{Introduction}

The dramatic swings in food and energy prices witnessed over the past few years have intensified the debate about the effect of fluctuations in commodity prices on underlying core measures of inflation.

An important piece of empirical evidence commonly cited in this debate is the fact that across many countries, oil and commodity price shocks in the 1970's fed through into higher and core inflation but the same commodity price movements have not led to higher core inflation over the past decade. (see e.g. Blanchard and Gali (2007); Blanchard and Riggi (2009); Mehra and Reilly (2009); Herrera and Pesavento (2009); Evans and Fisher (2011))

This joins empirical evidence of a marked change in the inflation process in many countries over the past few decades. Levin and Piger (2004) and Cecchetti and Debelle (2006) note a significant decline in the mean of the inflation process in many countries while Williams (2006) and Stock and Watson (2007) note that the persistence of inflation in the U.S. has

decreased and that inflation has become more difficult to forecast using its own lags. Kiley (2008), Fuhrer, Olivei, and Tootell (2009), Mehra and Reilly (2009), and Liu and Weidner (2011) all note how in the pre-1979 period, underlying core inflation in the U.S. was partially explained by past values of U.S. headline inflation and that a gap between core and headline inflation, possibly due to a commodity price shock, was partially erased by core converging towards headline. However, they show that in more recent data the tendency is for headline to converge towards core and that lagged values of headline inflation do not explain future values of core. Cecchetti and Moessner (2008) reach the same conclusion when looking across a broad range of both developed and developing countries.

One commonly cited reason for these changes in core-headline inflation dynamics is a change in monetary policy where policy became more credible and more focused on inflation stabilization. 1979 is commonly cited as a breakpoint in the U.S. inflation process because it coincides with the beginning of the Fed Chairmanship of Paul Volcker. Clarida, Galí, and Gertler (2000) estimate the Taylor rule policy reaction function with pre- and post-1979 
data and show that compared to the Fed of the 1970's, the Federal Reserve under Volcker and Greenspan placed a much greater weight on the inflation component of the policy rule. Lubik and Schorfheide (2004) extend this analysis and show that pre-1979 monetary policy led to indeterminacy whereby the insufficient response of the Fed Funds rate to an inflation shock led to higher inflation expectations and thus even higher inflation. ${ }^{1}$ Benati (2008) studies the persistence of inflation across many different monetary regimes and finds that inflation is purely forward looking and not subject to its own lags under stable monetary regimes with a clearly defined nominal anchor. This suggests that the high persistence in inflation in many countries during the 1970's whereby a temporary commodity price shock today would lead to higher underlying inflation in the future was a function of the monetary regime and under a stable regime with a clearly defined nominal anchor, a commodity price shock in the past should not affect pricing decisions now or into the future.

The reason that a change in the monetary regime can lead to a change in the inflation process and notably a change in the pass-through of spikes in commodity prices or headline inflation into core inflation is that monetary policy governs the response of inflation expectations following a commodity price shock. Monetary policy may not be able to prevent the initial spike in headline inflation following the commodity price shock, but it can affect expectations about future inflation. Leduc, Sill, and Stark (2007) analyze the behavior of inflation expectations taken from the Philadelphia Fed's Livingston Survey in the pre- and post-1979 data. While they find that inflation expectations are very persistent in the pre1979 data, they find that in more recent data any shocks to agents' inflation expectations quickly dissipate. Similarly Clark and Davig (2011) find that inflation expectations are much less volatile now than they are in the pre-1979 data, and Mehra and Herrington (2008), using

\footnotetext{
${ }^{1}$ The explanation that changes in monetary policy are responsible for the difference between pre- and post-1979 inflation dynamics is not without its critics. Orphanides (2004) repeats the exercise preformed in Clarida, Gali and Gertler (2000) using the real-time data available to policy makers at the time of monetary policy decisions and finds that while the weight on the output gap has fallen in the post-1979 period, the weight on inflation is unchanged. Similarly, Sims and Zha (2006) estimate a regime-switching model and find that while there was a change in the monetary policy reaction function in the pre- and post-1979 data, the change is not enough to explain the dramatic change in inflation dynamics and thus conjecture that much of the pre- and post-1979 difference is simply due to changes in exogenous shock processes.
} 
a structural VAR analysis, find that in the pre-1979 data, a shock to commodity prices led to a persistent increase in inflation expectations and a persistent decrease in the real interest rate, while in the post-1979 data, a shock to commodity prices only leads to a transitory increase in expectations and an increase in the real interest rate. Demertzis, Marcellino, and Viegi (2008) construct a measure of central bank credibility based on the sensitivity of long-term inflation expectations to movements in current inflation and show how U.S. inflation expectations became unanchored in the 1970's but that credibility was restored in the mid-1980's. Goodfriend and King (2005) examine statements by Federal Reserve policy makers and the transcripts from Fed meetings during the Volcker disinflation and show that the Fed of the early 1980's saw regaining Fed credibility as the key step towards controlling inflation expectations.

In a recent version of the World Economic Outlook, the IMF (2008) suggests that a spike in commodity prices is most likely to lead to second-round effects and increases in underlying core inflation in countries with a weak or uncredible central bank. Erceg and Levin (2003) and Andolfatto and Gomme (2003) construct models where agents are uncertain about the central bank's monetary policy stance and need to infer it from its past actions. In this framework, following a series of higher than expected observations of inflation, the central bank can lose control of inflation expectations and underlying inflation.

This paper will examine the link between shocks to commodity prices and underlying core inflation. We first use a structural VAR analysis to examine the effect of a shock to commodity prices on core inflation. Blanchard and Gali (2007) do a similar exercise to show that oil price shocks in the 1970's had a greater effect on inflation than similar shocks in the 2000's, but we examine this relationship in six different countries across multiple time periods. In each country we identify a date that represents a shift in the monetary regime. Impulse responses show that a commodity price shock had a large and significant effect on core inflation in the earlier period but when using data from after the shift in monetary regime, the effect is insignificant. 
We then construct a new Keynesian DSGE model that can replicate this empirical finding. The model is similar to Bodenstein, Erceg, and Guerrieri (2008) in that commodities are part of the consumption basket, leading to distinct core and headline inflation rates. In addition, agents know that inflation contains a permanent and a transitory component, but are not certain how much of the current observed inflation is permanent and how much is transitory. They must form beliefs about the permanent component from past observations of inflation. As in Isard, Laxton, and Eliasson (2001), Schorfheide (2005), Milani (2007), Andolfatto, Hendry, and Moran (2008), Lansing (2009), and Del Negro and Eusepi (2012) this leads to a channel whereby transitory shocks to inflation in the past can be misunderstood as shocks to the permanent component of inflation and thus can be incorporated into expectations of inflation in the future. As in all of these learning models, the Kalman gain parameter is one key parameter that determines how much of a shock to unexpected inflation is believed to be permanent and how much is believed to be transitory. This parameter measures the "anchoring" of inflation expectations.

Using Bayesian techniques we estimate this model using the same data that is used in the earlier structural VAR analysis. We estimate this Kalman gain parameter for each country both before and after the shift in monetary regime. In each case, the value of this Kalman parameter falls between the two regimes, indicating that inflation expectations become better anchored. Finally, impulse responses from simulations of the model show the change in this Kalman parameter drives the results we find in impulse responses from structural VARs. The reason a shock to commodity prices had a significant effect on underlying core inflation in the earlier regime but has an insignificant effect now is that between the two regimes, inflation expectations became better anchored.

The rest of this paper is organized as follows. Section 2 presents the structural VAR estimation of the response of core inflation to a commodity price shock. A theoretical model with distinct core and headline inflation rates is presented in sections 3 , and section 4 discusses the estimation of this model using Bayesian methods. Section 5 presents the 
response of core inflation to a commodity price shock as implied by simulations of the model and shows how only the version of the model that allows expectations to become better anchored can explain the results from structural VARs in section 2. Finally, section 6 concludes with some directions for further research.

\section{Empirical evidence}

To motivate the later analysis centered around the estimation of a DSGE model, in this section we present some evidence from structural VARs that shows that for many countries, there was a break in the response of underlying core inflation to a commodity price shock centered around that country's adoption of inflation targeting, or a similar shift towards a more credible monetary regime.

This evidence is found from the estimation of a four variable structural VAR consisting of core inflation, industrial production, commodity price inflation, and the 3-month nominal interest rate. ${ }^{2}$ This is also the order that the variables take for the Cholesky decomposition to convert the reduced-form VAR into a structural VAR.

In this analysis, we will consider not only a number of different countries, but a number of different time periods. The countries and time periods we consider are: the United States, 1965-1979 and 1984-2007; the UK, 1988-1997 and 1998-2007; Canada, 1974-1990 and 19912007; Norway, 1994-2000 and 2001-2007; Switzerland, 1992-1999 and 2000-2007; and Sweden, 1978-1992 and 1993-2007.

The 1965-1979 and 1984-2007 time periods are chosen for the United States because many researchers have found a significant break in the U.S. inflation process with the beginning of the Volcker Fed in late 1979, and thus the choice of these two time periods is meant to

\footnotetext{
${ }^{2}$ Since data on commodity price inflation is not available for most countries, the series on commodity price inflation is simply backed out of the observed series of headline inflation and core inflation. Specifically, using the same parameterizations that will be used later in the DSGE model, $\pi_{t}^{x}=\frac{\pi_{t}-\gamma \pi_{t}^{y}}{1-\gamma}$ where $\pi_{t}, \pi_{t}^{y}$, and $\pi_{t}^{x}$ are headline, core, and commodity price inflation, respectively, and $\gamma$ is the weight on core items in the total consumption basket.
} 
contrast the pre-Volcker Fed with the Fed of Paul Volcker and his successors. The response of these four variables, core inflation, industrial production, commodity price inflation, and the 3-month nominal interest rate, to a shock to commodity price inflation is given in figure 1. The figure shows that in the 1965-1979 period, the shock to commodity price inflation had a large and significant effect on core inflation, and it had a large and negative effect on industrial production. After 1984, the shock to commodity prices had a small and barely significant effect on core inflation and a similar small and barely significant effect on industrial production.

The results in figure 1 are similar to the results in Blanchard and Gali (2007) where they show that across a number of industrialized countries, an oil price shock had a greater positive effect on inflation and a greater negative effect on output in the 1970's than in recent decades. Blanchard and Gali attribute these findings to a number of factors, like better monetary policy, more flexible labor markets, an economy that is less dependent on oil, and just plain good luck, but for each country they assign 1984 as the breakpoint that divides the two subsamples.

In this analysis, we will assign the breakpoint for each country to be some significant date in the monetary history of that country. Figure 2 presents these same impulse responses calculated from UK data for the periods 1988-1997 and 1998-2007. These two subperiods are chosen because they are 9 years before and 9 years after the independence of the Bank of England in late 1997. The impulse responses in figure 2 shows that a shock to commodity price inflation had a positive and significant effect on core inflation in the pre-indpendence data but an insignificant effect on core inflation in the post independence data.

Similarly figure 3 presents these same response to a commodity price shock using Canadian data over the 1974-1990 and 1991-2007 subperiods. The Bank of Canada adopted inflation targeting in 1991, and thus the 1974-1990 and 1991-2007 periods compare the 16 years before inflation targeting in Canada and the 16 years after. Similar to the data from the U.S. or the UK in different time periods, before the monetary breakpoint, a shock to 
commodity price inflation had a positive and significant effect on core inflation but had an insignificant effect after.

Similar impulse responses for Norway over the 1994-2000 and 2001-2007 subperiods, Switzerland over the 1992-1999 and 2000-2007 subperiods, and Sweden over 1978-1992 and 1993-2007 are shown in figures 4, 5, and 6. The Bank of Norway adopted inflation targeting in 2001, the Swiss National Bank in 2000, and the Bank of Sweden in 1993. In each of these cases, a shock to commodity price inflation had a positive and significant effect on core inflation before the break in the monetary regime and an insignificant effect after.

\section{Theoretical model}

In this closed economy model there are two types of goods, finished goods and commodities. Monopolistically competitive firms combine capital and labor to produce finished goods. Firms set the price for this good in a Calvo (1983) style price setting framework. Households supply labor to firms and consume both finished goods and commodities. Their wages are determined by a Calvo style wage setting framework.

There is an endowment of a stock of commodities which is subject to an exogenous shock. The main purpose of the model is to investigate why a sudden spike in commodity prices might pass-though into the prices of finished goods.

Finally, there is a central bank that sets monetary policy according to a Taylor rule function of inflation and the output gap. Trend inflation is a term in this Taylor rule. It follows a unit root process, and is subject to exogenous shocks. Thus some exogenous shocks in the model lead to changes in the trend level of inflation and some just lead to transitory fluctuations of inflation around the trend.

Private agents know that there is a permanent and a transitory component to inflation, but in one version of the model, they cannot distinguish between the two with certainty. Thus when forming expectations of future inflation, agents use an error-correction model 
to update their beliefs about the permanent component. The Kalman gain parameter that agents use in this error-correction model measures the "anchoring" of inflation expectations, for it measures by how much agents update their long-term inflation expectations following a shock to current inflation.

\subsection{Production}

Final output, which is used for private consumption, investment, and government consumption, is produced through a CES combination of finished goods and commodities.

$$
C_{t}+I_{t}=\left[(\gamma)^{\frac{1}{\mu}}\left(y_{t}\right)^{\frac{\mu-1}{\mu}}+(1-\gamma)^{\frac{1}{\mu}}\left(x_{t}\right)^{\frac{\mu-1}{\mu}}\right]^{\frac{\mu}{\mu-1}}
$$

where $y_{t}$ is the quantity of finished goods in the household's consumption basket, $x_{t}$ is the quantity of commodities in the consumption basket, and $\mu$ is the elasticity of substitution between them.

From this CES aggregator function, the demand for finished goods or commodities is given by:

$$
\begin{aligned}
& y_{t}=\gamma\left(\frac{P_{t}^{y}}{P_{t}}\right)^{-\mu}\left(C_{t}+I_{t}\right) \\
& x_{t}=(1-\gamma)\left(\frac{P_{t}^{x}}{P_{t}}\right)^{-\mu}\left(C_{t}+I_{t}\right)
\end{aligned}
$$

where $P_{t}$ is the aggregate price level (which will be referred to from now on as the Consumer Price Index), $P_{t}^{y}$ is the price of finished goods (the Core CPI), and $P_{t}^{x}$ is the price of commodities. Substituting these demand functions into the CES aggregator in (1) shows that the CPI is simply a combination of the core CPI and commodity prices, $P_{t}=\left[\gamma\left(P_{t}^{y}\right)^{1-\mu}+(1-\gamma)\left(P_{t}^{x}\right)^{1-\mu}\right]^{\frac{1}{1-\mu}}$.

Three measures of inflation that we use in the upcoming analysis are headline inflation, $\pi_{t}=\frac{P_{t}}{P_{t-1}}-1$, core inflation, $\pi_{t}^{y}=\frac{P_{t}^{y}}{P_{t-1}^{y}}-1$, and commodity price inflation, $\pi_{t}^{x}=\frac{P_{t}^{x}}{P_{t-1}^{x}}-1$, 
where in a first-order approximation, $\pi_{t}=\gamma \pi_{t}^{y}+(1-\gamma) \pi_{t}^{x}$.

\subsubsection{Finished goods}

The quantity of finished goods in the consumption basket, $y_{t}$ is formed through a Dixit and Stiglitz (1977) aggregation of finished goods from firms $i \in\left[\begin{array}{ll}0 & 1\end{array}\right]$ :

$$
y_{t}=\left(\int_{0}^{1} y_{t}(i)^{\frac{\sigma-1}{\sigma}} d i\right)^{\frac{\sigma}{\sigma-1}}
$$

where $y_{t}(i)$ is the quantity produced by firm $i$, and $\sigma$ is the elasticity of substitution between finished goods from different firms.

From the aggregator function in (3), the demand for finished goods from home country firm $i$ is:

$$
y_{t}(i)=\left(\frac{P_{t}(i)}{P_{t}^{y}}\right)^{-\sigma} y_{t}
$$

where $P_{t}(i)$ is the price set by firm $i$, and $P_{t}^{y}=\left(\int_{0}^{1}\left(P_{t}(i)\right)^{1-\sigma} d i\right)^{\frac{1}{1-\sigma}}$.

The firm produces finished goods by combining capital, labor, and commodities with the following production technology:

$$
y_{t}(i)=A_{t}^{y} h_{t}(i)^{1-\alpha} k_{t}(i)^{\alpha}-\phi
$$

where $h_{t}(i)$ and $k_{t}(i)$ are the labor and capital employed by the firm in period $t, A_{t}^{y}$ is a productivity shock common to all firms, and $\phi$ is a small fixed cost term that is calibrated to ensure that firms earn zero profit in the steady state.

From the firm's cost minimization problem, the demand from firm $i$ for labor and capital are given by: 


$$
\begin{aligned}
h_{t}(i) & =(1-\alpha) \frac{M C_{t}}{W_{t}}\left(y_{t}(i)+\phi\right) \\
k_{t}(i) & =\alpha \frac{M C_{t}}{R_{t}}\left(y_{t}(i)+\phi\right)
\end{aligned}
$$

where $W_{t}$ is the wage rate, $R_{t}$ is the capital rental rate, $M C_{t}=\frac{1}{A_{t}^{y}}\left(\frac{W_{t}}{1-\alpha}\right)^{1-\alpha}\left(\frac{R_{t}}{\alpha}\right)^{\alpha}$.

\subsubsection{Commodities}

The economy is endowed with a supply of commodities, and this supply is subject to an exogenous shock:

$$
X_{t}=A_{t}^{x} \bar{X}
$$

where $A_{t}$ is a stochastic commodity supply shock. $\bar{X}$ is the steady state endowment of commodities.

Equilibrium in the commodity market is the point where the demand for commodities from households and firms is equal to the supply.

$$
x_{t}=X_{t}
$$

\subsection{Households}

Households, indexed $l \in\left[\begin{array}{ll}0 & 1\end{array}\right]$, supply labor, own capital, and consume from their labor income, rental income, interest on savings.

The household maximizes their utility function:

$$
\max \sum_{t=0}^{\infty} \beta^{t}\left[\ln \left(C_{t}(l)\right)-\psi\left(H_{t}(l)\right)^{\frac{1+\sigma_{H}}{\sigma_{H}}}\right]
$$

subject to their budget constraint: 


$$
\begin{aligned}
& P_{t} C_{t}(l)+P_{t} I_{t}(l)+B_{t+1}(l) \\
= & W_{t}(l) H_{t}(l)+R_{t} K_{t}(l)+P_{t}^{x} X_{t}(l)+\left(1+i_{t}\right) B_{t}(l)
\end{aligned}
$$

where $C_{t}(l)$ is consumption by household $l$ in period $t, H_{t}(l)$ is the household's labor effort in the period, $B_{t}(l)$ is the household's stock of bonds at the beginning of the period ${ }^{3}, W_{t}(l)$ is the wage paid for the household's heterogenous labor supply, $K_{t}(l)$ is the stock of capital owned by the household at the beginning of the period, and $P_{t}^{x} X_{t}(l)$ is the household's share of proceeds from the sale of the home country's commodity endowment.

The household's capital stock, $K_{t}(l)$, evolves according to the usual capital accumulation equation:

$$
K_{t+1}(l)=(1-\delta) K_{t}(l)+I_{t}(l)
$$

where market clearing in the market for physical capital requires that the sum of the physical capital stock across households is equal to the sum of physical capital demand across firms, $\int_{0}^{1} K_{t}(l) d l=\int_{0}^{1} k_{t}(i) d i$.

Each household supplies a differentiated type of labor. The function to aggregate the labor supplied by each household into the aggregate stock of labor employed by firms is:

$$
H_{t}=\left(\int_{0}^{1} H_{t}(l)^{\frac{\theta-1}{\theta}} d l\right)^{\frac{\theta}{\theta-1}}
$$

where market clearing in the labor market requires that $H_{t}=\int_{0}^{1} h_{t}(i) d i$. Since the household supplies a differentiated type of labor, it faces a downward sloping labor demand function:

$$
H_{t}(l)=\left(\frac{W_{t}(l)}{W_{t}}\right)^{-\theta} H_{t}
$$

\footnotetext{
${ }^{3}$ Market clearing in the bond market requires that the sum of bond holdings across all households equals zero, $\int_{0}^{1} B_{t}(l) d l=0$.
} 


\subsection{Monetary Policy}

The monetary policy instrument is the short-term nominal risk-free rate, $i_{t}$, which is determined by the central bank's Taylor rule function:

$$
i_{t+1}=i_{s s}+\theta_{p}\left(\pi_{t}-\bar{\pi}_{t}\right)+\theta_{y} \hat{y}_{t}+m_{t}
$$

where $\hat{y}_{t}=\frac{G D P_{t}}{G \tilde{D} P_{t}}-1$, where $G \tilde{D} P_{t}$ is the level of GDP at time $t$ in an economy with the same structure as the one just described and subject to the same shocks, only there are no price or wage frictions, $\xi_{p}=\xi_{w}=0$.

There are two types of exogenous monetary shocks in the Taylor rule function, one permanent and one transitory. As in Ireland (2007) and Cogley and Sbordone (2008) inflation contains both a trend and a cyclical component. The trend component to inflation is given by $\bar{\pi}_{t} \cdot{ }^{4}$ A shock to the trend inflation has a unit root, and the transitory monetary shock, $m_{t}$, is an i.i.d. process. Both are described in detail in the next section.

\subsection{Price and wage setting}

\subsubsection{Price setting by finished goods firms}

In period $t$, the firm will be able to change its price with probability $1-\xi_{p}$. Thus if allowed to change their price in period $t$, the firm will set a price to maximize:

$$
\max _{P_{t}^{d}(i)} \tilde{E}_{t} \sum_{\tau=0}^{\infty} \beta^{\tau}\left(\xi_{p}\right)^{\tau} \lambda_{t+\tau}\left\{P_{t}(i) y_{t+\tau}(i)-M C_{t+\tau} y_{t+\tau}(i)\right\}
$$

where $\lambda_{t}$ is the marginal utility of income in period $t$. As discussed in this paper's technical appendix, the firm that is able to change its price in period $t$ will set its price to:

\footnotetext{
${ }^{4}$ Trend inflation is similar to an inflation target. The idea is that there is some level of inflation with which the central bank is comfortable. When presenting the results from this model we show that if the central bank announces a formal inflation target, then trend inflation will center around this announced target and deviate very little.
} 


$$
P_{t}(i)=\frac{\sigma}{\sigma-1} \frac{\tilde{E}_{t} \sum_{\tau=0}^{\infty} \beta^{\tau}\left(\xi_{p}\right)^{\tau} \lambda_{t+\tau} M C_{t+\tau}\left(\frac{1}{P_{t+\tau}^{y}}\right)^{-\sigma} y_{t+\tau}}{\tilde{E}_{t} \sum_{\tau=0}^{\infty} \beta^{\tau}\left(\xi_{p}\right)^{\tau} \lambda_{t+\tau}\left(\frac{1}{P_{t+\tau}^{y}}\right)^{-\sigma} y_{t+\tau}}
$$

If prices are flexible, and thus $\xi_{p}=0$, then this expression reduces to:

$$
P_{t}(i)=\frac{\sigma}{\sigma-1} M C_{t}
$$

which says that the firm will set a price equal to a constant mark-up over marginal cost. Notice that instead of the usual rational expectations operator, expectations of future variables are denoted with $\tilde{E}_{t}(\cdot)$, where $\tilde{E}_{t}$ is a modified expectations operator. This modified operator will be explained later in this section.

Write the domestic price set by the firm that can reset prices in period $t$ as $\bar{P}_{t}(i)$ to denote that it is an optimal price. Firms that can reset prices in period $t$ will all reset to the same level, so $\bar{P}_{t}(i)=\bar{P}_{t}$. Substitute this optimal price into the price index $P_{t}^{y}=\left(\int_{0}^{1}\left(P_{t}(i)\right)^{1-\sigma} d i\right)^{\frac{1}{1-\sigma}}$ and use the fact that in any period $1-\xi_{p}$ percent of firms will reoptimize prices to derive an expression for the core price index, $P_{t}^{y}$ :

$$
P_{t}^{y}=\left(\xi_{p}\left(P_{t-1}^{y}\right)^{1-\sigma}+\left(1-\xi_{p}\right)\left(\bar{P}_{t}\right)^{1-\sigma}\right)^{\frac{1}{1-\sigma}}
$$

From equations (11) and (12) we can derive the usual New Keynesian Phillips Curve that relates core inflation this period to current marginal costs and the expected value of core inflation next period:

$$
\pi_{t}^{y}=\frac{\left(1-\xi_{p}\right)\left(1-\beta \xi_{p}\right)}{\xi_{p}}\left(m \hat{c}_{t}-\hat{p}_{t}^{y}\right)+\beta \tilde{E}_{t}\left(\pi_{t+1}^{y}\right)
$$

The details of this derivation can be found in the appendix. Notice that the modified operator, $\tilde{E}_{t}(\cdot)$ appears now in the New Keynesian Phillips Curve. Other than that, the Phillips curve is standard. 


\subsubsection{Wage setting by households}

In any given period, household $l$ faces a probability of $1-\xi_{w}$ of being able to reset their wage.

If household $l$ is allowed to reset their wages in period $t$ they will set a wage to maximize the expected present value of utility from consumption minus the disutility of labor.

$$
\tilde{E}_{t} \sum_{\tau=0}^{\infty} \beta^{\tau}\left(\xi_{w}\right)^{\tau}\left\{\lambda_{t+\tau} W_{t}(l) H_{t+\tau}(l)-\psi\left(H_{t+\tau}(l)\right)^{\frac{1+\sigma_{H}}{\sigma_{H}}}\right\}
$$

Thus after technical details which are located in the appendix, the household that can reset wages in period $t$ will choose a wage:

$$
W_{t}(l)^{\frac{\theta}{\sigma_{H}}+1}=\frac{\theta}{\theta-1} \frac{1+\sigma_{H}}{\sigma_{H}} \psi \frac{\tilde{E}_{t} \sum_{\tau=0}^{\infty} \beta^{\tau}\left(\xi_{w}\right)^{\tau}\left(W_{t+\tau}\right)^{\frac{\theta}{\sigma_{H}}+\theta}\left(H_{t+\tau}\right)^{\frac{1+\sigma_{H}}{\sigma_{H}}}}{\tilde{E}_{t} \sum_{\tau=0}^{\infty} \beta^{\tau}\left(\xi_{w}\right)^{\tau} \lambda_{t+\tau}\left(W_{t+\tau}\right)^{\theta} H_{t+\tau}}
$$

If wages are flexible, and thus $\xi_{w}=0$, this expression reduces to:

$$
W_{t}(l)=\frac{\theta}{\theta-1} \frac{\frac{1+\sigma_{H}}{\sigma_{H}} \psi\left(H_{t}\right)^{\frac{1}{\sigma_{H}}}}{\lambda_{t}}
$$

Thus when wages are flexible the wage rate is equal to a mark-up, $\frac{\theta}{\theta-1}$, multiplied by the marginal disutility of labor, $\frac{1+\sigma_{H}}{\sigma_{H}} \psi\left(H_{t}\right)^{\frac{1}{\sigma_{H}}}$, divided by the marginal utility of consumption, $\lambda_{t}$

Write the wage rate for the household that can reset wages in period $t, W_{t}(l)$, as $\bar{W}_{t}(l)$ to denote it as an optimal wage. Also note that all households that can reset wages in period $t$ will reset to the same wage rate, so $\bar{W}_{t}(l)=\bar{W}_{t}$.

All households face a probability of $\left(1-\xi_{w}\right)$ of being able to reset their wages in a given period, so by the law of large numbers $\left(1-\xi_{w}\right)$ of households can reset their wages in a given period. Substitute $\bar{W}_{t}$ into the expression for the aggregate wage rate $W_{t}=$ $\left(\int_{0}^{1} W_{t}(l)^{1-\theta} d l\right)^{\frac{1}{1-\theta}}$, to derive an expression for the evolution of the aggregate wage: 


$$
W_{t}=\left(\xi_{w}\left(W_{t-1}\right)^{1-\theta}+\left(1-\xi_{w}\right)\left(\bar{W}_{t}\right)^{1-\theta}\right)^{\frac{1}{1-\theta}}
$$

The New Keynesian Phillips Curve relating wage inflation this period to expected future wage inflation and the marginal disutility of labor this period is given by:

$$
\pi_{t}^{w}=\frac{\left(1-\xi_{w}\right)\left(1-\beta \xi_{w}\right)}{\xi_{w}}\left(\frac{\sigma_{H}}{\theta+\sigma_{H}}\right)\left(\frac{1}{\sigma_{H}} \hat{H}_{t}-\hat{\Lambda}_{t}-\hat{w}_{t}\right)+\beta \tilde{E}_{t}\left(\pi_{t+1}^{w}\right)
$$

where $\pi_{t}^{w}=\frac{W_{t+1}}{W_{t}}-1$.

\subsubsection{The modified expectations operator}

When agents form expectations, they know that inflation is made up of a permanent and a transitory component:

$$
\pi_{t}=\pi_{t}^{P}+\pi_{t}^{T}
$$

Agents know that the permanent component of inflation has a unit root and the transitory component decays at a rate $1-\psi$ where $\psi<1$. So agents' expectation of inflation in the next period is:

$$
\pi_{t+1}^{e}=\pi_{t}^{P}+\psi \pi_{t}^{T}
$$

Thus when agents form expectations about any variable, real or nominal, in the future, they do so assuming that inflation in period $t+i$ will be $\pi_{t+i}^{e}$. Thus the modified expectations operator, $\tilde{E}_{t}(\cdot)$, is defined as:

$$
\tilde{E}_{t}\left(\Theta_{t+j}\right)=E_{t}\left(\Theta_{t+j} \mid \pi_{t+i}^{e} \forall i=1 \ldots \infty\right)
$$

where $\tilde{E}_{t}\left(\Theta_{t+j}\right)$ is the expectation of the variable $\Theta$ in period $t+j$, where $\Theta$ is any variable in the model, and $E_{t}(\cdot)$ is the usual rational expectations operator. 
When this model is estimated, we will estimate it twice under two different assumptions about how well agents are able to distinguish between permanent and transitory components of inflation. In the first we assume that agent fully observe the trend level of inflation, $\bar{\pi}_{t}$, and so there is no uncertainty about the permanent component of inflation in equation (13), $\pi_{t}^{P}=\bar{\pi}_{t}$. Alternatively we assume that agents cannot observe trend inflation, and thus do not know with certainty the permanent component of inflation. In this case, agents form and update their beliefs about the permanent component of inflation using the following error-correction approach:

$$
\pi_{t}^{P}=\pi_{t-1}^{P}+\lambda\left(\pi_{t}-\tilde{E}_{t-1}\left(\pi_{t}\right)\right)
$$

where the Kalman gain parameter $\lambda$ is estimated from the data. This expression says that when agents see unexpected inflation, $\pi_{t}-\tilde{E}_{t-1}\left(\pi_{t}\right)$, they are unsure whether it is caused by a transitory shock or a shift in the trend level of inflation. Being unsure, they attribute the fraction $\lambda$ of the surprise in current inflation to a shift in the trend.

From the expression describing how agents form and update their beliefs about the permanent component of inflation, it is easy to see how this uncertainty about the trend level of inflation will result in even transitory fluctuations in inflation having a long-lasting effect. When agents do not observe the trend, the fraction $\lambda$ of any unexpected inflation will be assigned to beliefs about permanent component. Thus after a transitory shock like a commodity supply shock, if there were no uncertainty about the trend, then all of the resulting spike in inflation would be attributed to an increase in the transitory component, $\pi_{t}^{T}$ which agents would expect it to decay at the rate $1-\psi$. If however, agents do not observe the trend, then they will attribute a fraction $\lambda$ of the resulting spike in inflation to a change in the permanent component of inflation, which has a unit root, and thus agents' long-run inflation expectations increase by $\lambda$ multiplied by the temporary spike in inflation. These higher inflation expectations are then incorporated into price and wage demands through the modified operator $\tilde{E}_{t}(\cdot)$, and once incorporated into inflation expectations, second-round 
effects take hold that can turn a spike in prices following a temporary shock into a much more persistent increase in core inflation.

\section{Estimation}

We log-linearize the model around the steady state and then use Bayesian methods to fit the linearized model to 4 quarterly time series, the headline inflation rate, the core inflation rate, the deviation of GDP from its HP filtered trend, and the HP filtered trend of the headline inflation rate. The four variables in the model that we try to fit are the headline inflation rate $\left(\pi_{t}\right)$, the core inflation rate $\left(\pi_{t}^{y}\right)$, real GDP $\left(G D P_{t}=C_{t}+I_{t}\right)$, and trend inflation $\left(\bar{\pi}_{t}\right)$. Some of the structural parameters in the model are calibrated, but the parameters that describe the share of commodities in the consumption basket $(\gamma)$, the elasticity of substitution between finished goods and commodities $(\mu)$, and in the case where agents are unsure about the permanent component of inflation, the Kalman gain parameter $(\lambda)$, are estimated. The parameters describing the stochastic shocks in the model are estimated as well.

\subsection{Calibrated Parameter Values}

The various parameters used in the model and their values are listed in table 1 . The first five parameters, the discount factor, capital's share of income, the capital depreciation rate, the elasticity of substitution across varieties from different firms, the elasticity of substitution between labor from different households, and are all set to values that are commonly found in the literature.

The next two parameters, the Calvo wage and price stickiness parameters, are both set to 0.75 , implying that firms and households are able to change their prices and wages about once a year. In addition the coefficients on the inflation rate and the output gap in the central bank's Taylor rule function are set to their familiar values of 1.5 and 0.5 , respectively. 


\subsection{Estimated Parameters and Shock Processes}

Up to three structural parameters in the model are estimated, these are the share of commodities in the consumption basket $(\gamma)$, the elasticity of substitution between finished goods and commodities in the consumption basket $(\mu)$, and in the case where agents are unsure about the permanent component of inflation, the Kalman gain parameter $(\lambda)$.

In addition there are four shocks in the model: the commodity supply shock $\left(A_{t}^{x}\right)$, the productivity shock in the production of finished goods $\left(A_{t}^{y}\right)$, the permanent monetary shock (i.e. the shock to the inflation trend, $\left.\bar{\pi}_{t}\right)$, and the transitory monetary shock $\left(m_{t}\right)$. The commodity supply shock and the productivity shock each follow an AR(1) process, the transitory monetary shock is i.i.d. white noise, and the permanent monetary shock follows a smoothed unit-root process:

$$
\begin{aligned}
A_{t}^{x} & =\rho_{x} A_{t-1}^{x}+\varepsilon_{t}^{x} \\
A_{t}^{y} & =\rho_{y} A_{t-1}^{y}+\varepsilon_{t}^{y} \\
m_{t} & =\varepsilon_{t}^{m} \\
\bar{\pi}_{t}-\bar{\pi}_{t-1} & =\rho_{\pi}\left(\bar{\pi}_{t-1}-\bar{\pi}_{t-2}\right)+\varepsilon_{t}^{\pi}
\end{aligned}
$$

Using Bayesian methods, we estimate the two autoregressive parameters, $\rho_{x}$ and $\rho_{y}$, as well as the standard deviations of the first three exogenous shocks, $\varepsilon_{t}^{x}, \varepsilon_{t}^{y}, \varepsilon_{t}^{m}$. Since trend inflation is one of the variables that we try to fit in the model and is completely described by an exogenous shock process, we calibrate the model to match the observed values of $\rho_{\pi}$ and the standard deviation of $\varepsilon_{t}^{\pi}$.

The prior distribution and posterior modes of the estimated parameters and shock processes are presented in tables 2 and 3 . The model is estimated four times for each of the six countries in the study. In each country, the model is estimated both before and after the country- 
specific break point in the inflation process. ${ }^{5}$ Furthermore, in each time period the model is estimated twice, once under the assumption that agents know the permanent component of inflation and one where they do not and need to learn it through a Kalman learning process.

The priors are the same for every estimation. The results in tables 2 and 3 show how the key parameters of the model change between the earlier and later time periods, and also how these key parameters depend on whether we are assuming that agents have complete information about the permanent and transitory components of inflation or if their information is incomplete.

First, it is interesting to note how the estimated standard deviations of the four shocks in the model drop considerably between the earlier and later periods. This of course resulted in less volatile business cycles, and appears to be due to both good luck (lower variance of commodity supply shocks, $\varepsilon_{t}^{x}$, and productivity shocks, $\varepsilon_{t}^{y}$ ), and more consistent monetary policy (lower variance of both the transitory and permanent monetary shocks, $\varepsilon_{t}^{m}$ and $\varepsilon_{t}^{\pi}$ ). For the most part, the variance of the exogenous shocks does not depend on the assumption of complete or incomplete information.

However, the estimated persistence of the shock processes does seem to depend on whether we are assuming agents have complete or incomplete information about the permanent component of inflation. The estimated autoregressive term in the shock processes $\left(\rho_{x}\right.$ and $\left.\rho_{y}\right)$ is higher under the assumption that agents have complete information about the permanent component of inflation. As will be discussed in the next section, the persistence of inflation is higher under the assumption that agents have incomplete information, since they will observe unexpected inflation due to a transitory shock but attribute some of it to a change in the permanent component of inflation. Thus when information about the permanent component is incomplete, even a transitory shock to inflation can be incorporated into long-run inflation expectations.

\footnotetext{
${ }^{5}$ So the model is estimated for the United States, 1965-1979 and 1984-2007; the UK, 1988-1997 and 1998-2007; Canada, 1974-1990 and 1991-2007; Norway, 1994-2000 and 2001-2007; Switzerland, 1992-1999 and 2000-2007; and Sweden, 1978-1992 and 1993-2007.
} 
As will be discussed in the next section, observed inflation tends to be fairly persistent. When using Bayesian methods to estimate shock processes the estimation process forces the parameters of the shock process, $\rho_{x}$ and $\rho_{y}$, to be high in order to match this observed persistence. ${ }^{6}$ The assumption of incomplete information adds a channel to increase the persistence of inflation, and as a result, the estimation process does not force the parameters of the shock process, $\rho_{x}$ and $\rho_{y}$, to be as high under the assumption of incomplete information.

Finally, the most interesting result from the estimations presented in tables 2 and 3 is the change in the Kalman gain parameter, $\lambda$, between the earlier and later time periods. This parameter measures what fraction of an unexpected jump in inflation agents attribute to a change in the permanent component. Thus $\lambda$ measures how well anchored are inflation expectations in response to surprises in observed inflation. In every case, the estimated $\lambda$ parameter falls between the earlier and the later periods, indicating that inflation expectations are becoming better anchored. In the U.S. prior to 1979, if agents observed that actual inflation turned out to be 1 percentage point higher than expected and they would raise their beliefs about the permanent component of inflation, by 0.22 percentage points.After 1984, agents would only increase their long term inflation expectations by 0.05 percentage points in response to the same inflation surprise.

\section{Results}

The results from this estimated model are presented in two parts. First we present impulse responses from simulations of the model calibrated with the estimated parameters from the last section. Here we examine the response of core inflation to a shock to commodity price inflation, exactly the same as the impulse responses found through structural VARs in section 2. The earlier results derived from structural VARs showed that across many countries, there was a break point in the inflation process and before this date, a commodity price shock had a significant effect on core inflation, but after this break point the effect was insignificant.

\footnotetext{
${ }^{6}$ This is what Fuhrer $(2006,2011)$ refers to as "inherited" inflation persistence.
} 
The results from the simulated model show the same thing, and more importantly, show that only the model that allows agents to have incomplete information about the permanent and transitory components of inflation can replicate this result, and the driving force behind the earlier empirical results is simply a fall in the $\lambda$ parameter.

Then we examine the volatility and persistence of both headline and core inflation and show how around the same breakpoint there was a significant change in these moments. The volatility and persistence of headline inflation dropped significantly, and the relative volatility of core inflation (the volatility of core inflation relative to the volatility of headline inflation) also shows a significant drop. The moments from simulations of the model show that again, only the model where agents have incomplete information about the permanent component of inflation can replicate this observation, and that these observations from the data are driven by a change in the anchoring of inflation expectations.

\subsection{Impulse responses}

Impulse responses, taken from simulations of the model, are presented in figures 7-12. Figure 7 presents the impulse responses taken from simulations of the model parameterized using estimated parameters from the U.S. that appear in table 2. The four impulse response diagrams in the top half of the figure are taken from simulations of the model assuming that agents have complete information about the permanent and transitory components of inflation, and the four diagrams in the bottom half of the table are from simulations of the model assuming incomplete information. In each set of diagrams the red dashed line represents the model with parameters estimated from the earlier time period and the blue solid line represents those from the later period.

Each set of impulse responses charts the response of commodity price inflation, core inflation, GDP, and the risk free rate, to a negative commodity supply shock that in the first period leads to a $1 \%$ increase in commodity price inflation, and thus the simulated impulse responses in figure 7 measure the same responses as those estimated from a structural VAR in 
figure 1, and the parameters used to construct the simulated impulse responses are estimated from the same data that is used in the estimation of the structural VARs.

A comparison of the simulated impulse responses in figure 7 with those estimated from a structural VAR in figure 1 show that only the model with incomplete information can replicated the fact that a $1 \%$ increase in commodity price inflation led to a $0.3 \%$ increase in core inflation in the pre-1979 data and barely any change in core inflation in the post-1984 data. The model where agents fully observe the permanent and transitory components of inflation cannot replicate this, and in the complete information model, the response of core inflation is about the same in both periods.

The reason that there is a difference between the simulated impulse responses from the earlier and later time periods in the incomplete information model but not in the complete information model is due to the Kalman gain parameter, $\lambda$, and the estimated changes in this parameter between the two periods. As discussed earlier, the estimate value of this parameter is around 0.22 in the pre-1979 data but only 0.05 in the post-1984 data. Thus the commodity price shock lead to a $1 \%$ increase in unexpected inflation. In the earlier time period, given the Kalman gain parameter of 0.22 , agents would observe a $1 \%$ increase in unexpected inflation and raise their long-term inflation expectations by $0.22 \%$. These high inflation expectations would then be incorporated into the price and wage setting process and would result in higher core inflation. In the later period, when the Kalman gain parameter is only 0.05 these second-round effects are nearly shut off. The same increase in unexpected inflation would lead to only a $0.05 \%$ increase in long term inflation expectations.

Thus when the estimated Kalman gain parameter is only 0.05 , the second round effects that lead to a large and persistent increase in core inflation following a commodity price shock are nearly shut-off. Similarly, when agents have complete information about the permanent and transitory components of inflation, the effect of the commodity price shock on inflation expectations is shut down. Agents observe the commodity price shock but recognize it as transitory and so do not change their long-term inflation expectations, preventing the shock 
from being incorporated into price and wage demands.

Similar impulse responses for the UK, Canada, Norway, Switzerland, and Sweden are shown in figures 8 and 12. Even though in each country there is a different date that divides the earlier and later time periods, the story is always the same. The earlier impulse responses estimated from structural VARs showed that in the earlier period, a commodity price shock had a positive and significant effect on core inflation, but had almost no effect after the change in monetary regime. The simulated impulse responses using parameters estimated from the same data shows that only the model where agents are unsure about the permanent and transitory components of inflation can replicate this result, and the difference between the response of core inflation in the earlier and later time periods is entirely due to the difference in the estimated Kalman gain parameter between the earlier and later time periods.

\subsection{Inflation persistence and volatility}

The volatility and persistence of headline inflation, core inflation, commodity price inflation, and $G D P$ both in the data and in simulations of the model are presented in tables 4 and 5. For each of the countries in the study, the table reports the volatility and persistence of inflation and GDP during both the earlier and later time periods, and then reports the volatility and persistence of these variables taken from simulations of the model that is parameterized with the estimated parameters reported in tables 2 and 3.

Here we again compare the performance of the model where agents have complete information about the permanent component of inflation against the performance of the model where they do not. In almost every country (all except for Norway) there was a sizeable fall in inflation volatility between the earlier and later time periods, and this fact is replicated in simulations of both versions of the model.

While both the complete and the incomplete information versions of the model can replicate the fall in the volatility of headline inflation between the two time periods, only the 
model with incomplete information can replicate the high relative volatility of core inflation in the earlier time period and the subsequent fall in that relative volatility in the later period. This, of course, is due to the fact that in the model assuming incomplete information, agents attribute a fraction $\lambda$ of an increase in unexpected inflation to a change in the permanent component, even if the unexpected inflation was due to a purely transitory shock. As a result, inflation expectations, and thus core inflation should be much more volatile in the model where agents cannot perfectly distinguish between permanent and transitory components than in the model where they can. In the U.S., prior to 1979 , core inflation was $88 \%$ as volatile as headline inflation. In the model where agents have complete information about the permanent and transitory components of inflation, core inflation is only $60 \%$ as volatile, but in the model where agents can't perfectly distinguish between the permanent and transitory components, core inflation is $87 \%$ as volatile.

Similarly, the relative volatility of core inflation should fall as $\lambda$ falls and inflation expectations become better anchored. In nearly every country in the study, there is a sizable fall in the relative volatility of core inflation in the data between the earlier and later time periods. Simulations of the model under complete information also show some reduction of the relative volatility of core inflation between these two periods, but the fall in the relative volatility in simulations of the model is not as great as in the data. Since in every country in the study there was a fall in $\lambda$ between the two time periods, inflation expectations are more anchored and thus core inflation is less volatile in the later time period.

Similarly, for every country, headline inflation was very persistent in the early sample (in most cases the first-order autocorrelation coefficient is greater than 0.5). Only the model with incomplete information can replicate this high persistence in inflation in the earlier period. This is of course due to the fact that in the incomplete information version of the model when $\lambda$ is high, a fluctuation in inflation that is due to a purely transitory shock is still incorporated into beliefs about the permanent component of inflation and thus longterm inflation expectations. From there, second-round effects take hold and the transitory 
fluctuation in inflation can lead to a persistent string of wage and price increases. Of course this doesn't happen in the version of the model where agents have complete information about the permanent component of inflation and as a result inflation persistence is never that high.

In addition, the data shows that the persistence of inflation fell quite substantially between the earlier and the later subperiods. The version of the model with complete information cannot replicate this fall, but the model with incomplete information can since the fall in $\lambda$ meant inflation expectations were better anchored, and thus the second-round effects whereby a transitory shock can lead to a long-lasting increase in inflation is shut down.

\section{Summary and conclusion}

This paper provides a mechanism through which fluctuations in inflation caused by purely transitory shocks can become incorporated into long-lasting inflation expectations. To use the language from Ireland (2007) and Cogley and Sbordone (2008), inflation has a trend and a cyclical component. In this model, private agents cannot distinguish between the two, and so a cyclical fluctuation in inflation may be confused for a fluctuation in the trend component. When this happens agents will update their expectations about future inflation and these expectations are incorporated into price and wage setting decisions, and thus the mere expectation of higher prices in the future can lead to higher prices today.

Within this framework we can understand the effect of a purely transitory shock to commodity prices on underlying core inflation. Impulse responses derived from a structural VAR model show that across many countries there was a break in the response of core inflation to a shock to commodity prices. In an earlier period, a shock to commodity prices would lead to a large and significant increase in core inflation, but in later periods, the effect was insignificant. We then conjectured that this change in the impulse responses must be due to a shift in the monetary regime which led to more anchored inflation expectations. 
The estimation of a large-scale DSGE model that incorporates both headline and core inflation confirmed this. In each country in the study, Bayesian estimation reveals that there was a change between the earlier and the later periods in the parameter that governs the anchoring of expectations. Furthermore, with impulse responses derived from simulations of this DSGE model, only the model that incorporates this confusion about the trend and cyclical component can explain the fact that the effect of commodity price shocks on core inflation was significant under the earlier monetary regime but not anymore, and the reason for this change is the change in the anchoring of inflation expectations.

An interesting direction for further research would be to look at this same question, how do transitory commodity price fluctuations lead to a long-lasting increase in inflation expectations and core inflation, with a small open economy model. The small open economy takes commodity prices in the foreign currency as given, but the price in the home currency depends on fluctuations in the nominal exchange rate. This paper uses the adoption of inflation targeting as a break in the monetary regime, and shows that this break in the monetary policy regime led to a change in the pass-through of transitory commodity price fluctuations into core inflation. An interesting direction for further research would be to instead consider a central bank's exchange rate policy, and through estimating a small open economy version of this model, see how exchange rate policy might affect how foreign commodity price shocks pass-through into domestic inflation expectations and core inflation.

Another interesting direction for further research relates to the optimal conduct of monetary policy when private agents can't distinguish between the trend and cyclical components of inflation and thus inflation expectations can become unanchored. Orphanides and Williams $(2004,2007)$ and Gaspar, Smets, and Vestin $(2006,2011)$ present models where agents have imperfect information about the parameters in the central bank's policy rule function, or where they are unsure if a shock to inflation is transitory or permanent. These models all show that in this environment, the central bank should be more aggressive when responding to changes in inflation. 
Posen (2011) argues that the central bank's reaction to a transitory increase in prices should depend on the anchoring of inflation expectations. If long-term inflation expectations are very sensitive to fluctuations in current inflation, then a central bank will want to be very aggressive in responding to transitory increases in inflation, but as expectations become better anchored then the central bank may not want to be as aggressive in responding to transitory movements in prices. As mentioned in the introduction, in a recent version of the World Economic Outlook, the IMF (2008) suggests that a spike in commodity prices is most likely to lead to second-round effects and increased underlying core inflation in countries with a weak or uncredible central bank. Thus an interesting direction for further research would be to quantify how a central bank's optimal response to a purely transitory shock to inflation, like a commodity price shock, is a function of the anchoring of inflation expectations. 


\section{References}

Andolfatto, D., And P. Gomme (2003): "Monetary policy regimes and beliefs," International Economic Review, 44, 1-30.

Andolfatto, D., S. Hendry, and K. Moran (2008): "Are inflation expectations rational?," Journal of Monetary Economics, 55, 406-422.

Benati, L. (2008): "Investigating inflation persistence across monetary regimes," The Quarterly Journal of Economics, 123, 1005-1060.

Blanchard, O. J., And J. Gali (2007): "The Macroeconomic Effects of Oil Shocks: Why are the 2000s so different from the 1970s?," NBER Working Paper No. 13368.

Blanchard, O. J., And M. Riggi (2009): "Why are the 2000s so different from the 1970s? A structural interpretation of changes in the macroeconomic effects of oil prices," NBER Working Paper No. $1546 \%$.

Bodenstein, M., C. J. Erceg, and L. Guerrieri (2008): "Optimal monetary policy with distinct core and headline inflation rates," Journal of Monetary Economics, 55, 518535 .

Calvo, G. A. (1983): "Staggered Prices in a Utility-Maximizing Framework," Journal of Monetary Economics, 12, 383-398.

Cecchetti, S. G., And G. Debelle (2006): "Has the Inflation Process Changed?," Economic Policy, pp. 311-352.

Cecchetti, S. G., And R. Moessner (2008): "Commodity prices and infaltion dynamics," BIS Quarterly Review, pp. 55-66.

Clarida, R., J. Galí, and M. Gertler (2000): "Monetary Policy Rules and Macroeconomic Stability: Theory and Some Evidence," Quarterly Journal of Economics, 115, $147-180$.

Clark, T. E., and T. Davig (2011): "Decomposing the declining volatility of long-term infaltion expectations," Journal of Economic Dynamics and Control, 35, 981-999.

Cogley, T., and A. M. Sbordone (2008): "Trend inflation, indexation, and inflation persistence in the new Keynesian Phillips Curve," The American Economic Review, 98(5), $2101-2126$.

Del Negro, M., And S. Eusepi (2012): "Fitting observed inflation expectations," Journal of Economic Dynamics and Control, forthcoming.

Demertzis, M., M. Marcellino, and N. Viegi (2008): "A measure for credibility: Tracking U.S. monetary developments," De Nederlandsche Bank Working Paper No. $187 / 2008$. 
Dixit, A. K., And J. E. Stiglitz (1977): "Monopolistic Competition and Optimum Product Diversity," The American Economic Review, 67, 297-308.

Erceg, C. J., And A. T. Levin (2003): "Imperfect credibility and inflation persistence," Journal of Monetary Economics, 50, 915-944.

Evans, C. L., And J. D. Fisher (2011): "What are the implications of rising commodity prices for inflation and monetary policy?," Chicago Fed Letter No. 286.

Fuhrer, J., G. Olivei, and G. M. Tootell (2009): "Empirical Estimates of Changing Inflation Dynamics," Federal Reserve Bank of Boston Working Peper No. 09-4.

Fuhrer, J. C. (2006): "Intrinsic and Inherited Inflation Persistence," International Journal of Central Banking, 2(3), 49-86.

(2011): "Inflation Persistence," in Handbook of Monetary Economics, ed. by B. M. Friedman, and M. Woodford, vol. 3A, pp. 423-486. North Holland.

Gaspar, V., F. Smets, and D. Vestin (2006): "Adaptive Learning, Persistence, and Optimal Monetary Policy," Journal of the European Economic Association, 4, 376-385.

(2011): "Inflation Expectations, Adaptive Learning, and Optimal Monetary Policy," in Handbook of Monetary Economics, ed. by B. M. Friedman, and M. Woodford, vol. 3B, pp. 1055-1096. North Holland.

Goodfriend, M., and R. G. King (2005): "The incredible Volcker disinflation," Journal of Monetary Economics, 52, 981-1015.

Herrera, A. M., and E. Pesavento (2009): "Oil price shocks, Systemastic monetary policy, and the Great Moderation," Macroeconomic Dynamics, 13, 107-137.

Ireland, P. N. (2007): "Changes in the Federal Reserves's inflation target: Causes and consequences," Journal of Money, Credit, and Banking, 39, 1851-1882.

Isard, P., D. Laxton, and A.-C. Eliasson (2001): "Inflation targeting with NAIRU uncertainty and endogenous policy credibility," Journal of Economic Dynamics and Control, $25,115-148$.

KILEy, M. T. (2008): "Estimating the common trend rate of inflation for consumer prices and consumer prices excluding food and energy prices," Federal Reserve Board, Finance and Economics Discussion Series, 2008-38.

LANSing, K. J. (2009): "Time varying U.S. inflation dynamics and the new Keynesian phillips curve," Review of Economic Dynamics, 12, 304-326.

Leduc, S., K. Sill, and T. Stark (2007): "Self-fulfilling expectations and the inflation of the 1970's: Evidence from the Livingston Survey," Journal of Monetary Economics, 54, 433-459. 
Levin, A. T., and J. M. Piger (2004): "Is inflation persistence intrinsic in industrial economies," ECB Working Paper No. 334.

Liu, Z., And J. Weidner (2011): "Does Headline Inflation Converge to Core?," Federal Reserve Bank of San Francisco Economic Letter 2011-24.

Lubik, T., and F. Schorfheide (2004): "Testing for Indeterminacy: An Application to U.S. Monetary Policy," The American Economic Review, 94(1), 190-217.

Mehra, Y. P., and C. Herrington (2008): "On the sources of movements in inflation expectations: A few insights from a VAR model," Federal Reserve3 Bank of Richmond Economic Quarterly, 94(2), 121-146.

Mehra, Y. P., And D. Reilly (2009): "Short-term headline-core inflation dynamics," Federal Reserve3 Bank of Richmond Economic Quarterly, 95(3), 289-313.

Milani, F. (2007): "Expectations, learning and macroeconomic persistence," Journal of Monetary Economics, 54, 2065-2082.

Orphanides, A. (2004): "Monetary Policy Rules, Macroeconomic Stability, and Inflation: A view from the trenches," Journal of Money, Credit, and Banking, 36(2), 151-175.

Orphanides, A., and J. C. Williams (2004): "Imperfect Knowledge, Inflation Expectations, and Monetary Policy," in The Inflation-Targeting Debate, ed. by B. S. Bernanke, and M. Woodford, pp. 201-246. University of Chicago Press.

(2007): "Robust monetary policy with imperfect knowledge," Journal of Monetary Economics, 54, 1406-1435.

Posen, A. (2011): "The Soft Tyranny of Inflation Expectations," International Finance, 0, $1-26$.

Schorfheide, F. (2005): "Learning and monetary policy shifts," Review of Economic Dynamics, 8, 392-419.

Sims, C. A., And T. Zha (2006): "Where there regime switches in U.S. monetary policy?," The American Economic Review, 96(1), 54-80.

Stock, J. H., and M. W. Watson (2007): "Why has U.S. infaltion become harder to forecast?," Journal of Money, Credit, and Banking, 39(1), 3-33.

The International Monetary Fund (2008): "Is Inflation Back?: Commodity Prices and Inflation," World Economic Outlook, pp. 83-137.

Williams, J. C. (2006): "The Phillips curve in an era of well anchored inflation expectations," Federal Reserve Bank of San Franciso Unpublished Working Paper. 


\section{A Technical Appendix}

This appendix will present some of the more technical derivations in the paper related to the nominal rigidities present in the model. The first section in the appendix will solve for the household's optimal wage and present the derivation of the New Keynesian Phillips Curve (NKPC) for wage inflation. The second section will solve for the firm's optimal price and present the derivation of the NKPC for core inflation.

\section{A.1 Sticky Wages}

In any given period, household $l$ faces a probability of $1-\xi_{w}$ of being able to reset their wage.

If household $l$ is allowed to reset their wages in period $t$ they will set a wage to maximize the expected present value of utility from consumption minus the disutility of labor.

$$
\tilde{E}_{t} \sum_{\tau=0}^{\infty} \beta^{\tau}\left(\xi_{w}\right)^{\tau}\left\{\lambda_{t+\tau} W_{t}(l) H_{t+\tau}(l)-\psi\left(H_{t+\tau}(l)\right)^{\frac{1+\sigma_{H}}{\sigma_{H}}}\right\}
$$

where $\lambda_{t+\tau}$ is the marginal utility of consumption in period $t+\tau{ }^{7}$

The imperfect combination of labor from different households is described in (9). Use this function to derive the demand function for labor from a specific household:

$$
H_{t}(l)=\left(\frac{W_{t}(l)}{W_{t}}\right)^{-\theta} H_{t}
$$

where $W_{t}=\left(\int_{0}^{n} W_{t}(l)^{1-\theta} d l\right)^{\frac{1}{1-\theta}}$ is the average wage across households, and $H_{t}$ is aggregate labor supplied by all households.

Substitute the labor demand function into the maximization problem to express the maximization problem as a function of one choice variable, the wage rate, $W_{t}(l)$ :

\footnotetext{
${ }^{7}$ We assume complete contingent claims markets among households within a country. This implies that the marginal utility of consumption is the same across all households within a country, regardless of their income. Therefore the total utility from the consumption of labor income in any period is simply the country specific marginal utility of comsumption, $\lambda_{t}$, multiplied by the household's labor income, $W_{t}(l) N_{t}(l)$.
} 


$$
\tilde{E}_{t} \sum_{\tau=0}^{\infty} \beta^{\tau}\left(\xi_{w}\right)^{\tau}\left\{\lambda_{t+\tau} W_{t}(l)\left(\frac{W_{t}(l)}{W_{t+\tau}}\right)^{-\theta} H_{t+\tau}-\psi\left(\left(\frac{W_{t}(l)}{W_{t+\tau}}\right)^{-\theta} H_{t+\tau}\right)^{\frac{1+\sigma_{H}}{\sigma_{H}}}\right\}
$$

After some rearranging, the first order condition of this problem is:

$$
W_{t}(l)^{\frac{\theta}{\sigma_{N}}+1}=\frac{\theta}{\theta-1} \frac{1+\sigma_{H}}{\sigma_{H}} \psi \frac{\tilde{E}_{t} \sum_{\tau=0}^{\infty} \beta^{\tau}\left(\xi_{w}\right)^{\tau}\left(W_{t+\tau}\right)^{\frac{\theta}{\sigma_{H}}+\theta}\left(H_{t+\tau}\right)^{\frac{1+\sigma_{H}}{\sigma_{H}}}}{\tilde{E}_{t} \sum_{\tau=0}^{\infty} \beta^{\tau}\left(\xi_{w}\right)^{\tau} \lambda_{t+\tau}\left(W_{t+\tau}\right)^{\theta} H_{t+\tau}}
$$

If wages are flexible, and thus $\xi_{w}=0$, this expression reduces to:

$$
W_{t}(l)=\frac{\theta}{\theta-1} \frac{\frac{1+\sigma_{H}}{\sigma_{H}} \psi\left(H_{t}\right)^{\frac{1}{\sigma_{H}}}}{\lambda_{t}}
$$

Thus when wages are flexible the wage rate is equal to a mark-up, $\frac{\theta}{(\theta-1)}$, multiplied by the marginal disutility of labor, $\frac{1+\sigma_{H}}{\sigma_{H}} \psi\left(H_{t}\right)^{\frac{1}{\sigma_{H}}}$, divided by the marginal utility of consumption, $\lambda_{t}$

Write the wage rate for the household that can reset wages in period $t, W_{t}(l)$, as $\bar{W}_{t}(l)$ to denote it as an optimal wage. Also note that all households that can reset wages in period $t$ will reset to the same wage rate, so $\bar{W}_{t}(l)=\bar{W}_{t}$.

All households face a probability of $\left(1-\xi_{w}\right)$ of being able to reset their wages in a given period, so by the law of large numbers $\left(1-\xi_{w}\right)$ of households can reset their wages in a given period. The wages of the other $\xi_{w}$ will automatically reset by the previous periods inflation rate.

So substitute $\bar{W}_{t}$ into the expression for the average wage rate $W_{t}=\left(\int_{0}^{n} W_{t}(l)^{1-\theta} d l\right)^{\frac{1}{1-\theta}}$, to derive an expression for the evolution of the average wage:

$$
W_{t}=\left(\xi_{w}\left(W_{t-1}\right)^{1-\theta}+\left(1-\xi_{w}\right)\left(\bar{W}_{t}\right)^{1-\theta}\right)^{\frac{1}{1-\theta}}
$$




\section{A.1.1 Derivation of the NKPC for wage inflation}

As presented in the text, the optimal wage in real terms is given by:

$$
w_{t}(l)^{\frac{\theta}{\sigma_{H}}+1}=\frac{\theta}{\theta-1} \frac{1+\sigma_{H}}{\sigma_{H}} \psi \frac{\tilde{E}_{t} \sum_{\tau=0}^{\infty} \beta^{\tau}\left(\xi_{w}\right)^{\tau}\left(w_{t+\tau} \Pi_{t, t+\tau}\right)^{\frac{\theta}{\sigma_{H}}+\theta}\left(H_{t+\tau}\right)^{\frac{1+\sigma_{H}}{\sigma_{H}}}}{\tilde{E}_{t} \sum_{\tau=0}^{\infty} \beta^{\tau}\left(\xi_{w}\right)^{\tau} \Lambda_{t+\tau}\left(w_{t+\tau}\right)^{\theta}\left(\Pi_{t, t+\tau}\right)^{\theta-1} H_{t+\tau}}
$$

Furthermore, the expression for the evolution of the average wage in real terms is:

$$
w_{t}=\left(\xi_{w}\left(\frac{w_{t-1}}{\pi_{t}}\right)^{1-\theta}+\left(1-\xi_{w}\right)\left(\tilde{w}_{t}\right)^{1-\theta}\right)^{\frac{1}{1-\theta}}
$$

Recall that $w_{t}(l)=\tilde{w}_{t}$ for all households that can change their wage in period $t$. The linearized form of these two expressions is given by:

$$
\begin{aligned}
\left(\frac{\theta}{\sigma_{H}}+1\right) \hat{w}_{t}^{*} & =\tilde{E}_{t} \sum_{\tau=0}^{\infty} \beta^{\tau}\left(\xi_{w}\right)^{\tau}\left(\begin{array}{c}
\left(1-\beta \xi_{w}\right)\left(\left(\frac{\theta}{\sigma_{H}}\right) \hat{w}_{t+\tau}+\left(\frac{1}{\sigma_{H}}\right) \hat{H}_{t+\tau}-\Lambda_{t+\tau}\right) \\
+\beta \xi_{w}\left(\frac{\theta}{\sigma_{H}}+1\right) \pi_{t+\tau+1}
\end{array}\right) \\
\hat{w}_{t} & =\left(1-\xi_{w}\right) \hat{w}_{t}^{*}+\xi_{w}\left(\hat{w}_{t-1}-\pi_{t}\right)
\end{aligned}
$$

The linearized form of the expression for the real wage can be rewritten as:

$$
\hat{w}_{t}^{*}=\left(1-\beta \xi_{w}\right)\left(\frac{\sigma_{H}}{\theta+\sigma_{H}}\right)\left(\left(\frac{\theta}{\sigma_{H}}\right) \hat{w}_{t}+\left(\frac{1}{\sigma_{H}}\right) \hat{H}_{t}-\Lambda_{t}\right)+\beta \xi_{w} \pi_{t+1}+\beta \xi_{w} \tilde{E}_{t}\left(\hat{w}_{t+1}^{*}\right)
$$

Furthermore note that the linearization of the wage evolution equation can be rewritten as $\hat{w}_{t}^{*}=\frac{1}{1-\xi_{w}} \hat{w}_{t}-\frac{\xi_{w}}{1-\xi_{w}}\left(\hat{w}_{t-1}-\pi_{t}\right)$ and $\tilde{E}_{t}\left(\hat{w}_{t+1}^{*}\right)=\frac{1}{1-\xi_{w}} \hat{w}_{t+1}-\frac{\xi_{w}}{1-\xi_{w}}\left(\hat{w}_{t}-\tilde{E}_{t}\left(\pi_{t+1}\right)\right)$. Then after a few substitutions and a lot of algebra, the New Keynesian Phillips Curve equation describing wage inflation is given by:

$$
\pi_{t}^{w}=\frac{\left(1-\xi_{w}\right)\left(1-\beta \xi_{w}\right)}{\xi_{w}}\left(\frac{\sigma_{H}}{\theta+\sigma_{H}}\right)\left(\left(\frac{1}{\sigma_{H}}\right) \hat{H}_{t}-\hat{\Lambda}_{t}-\hat{w}_{t}\right)+\beta \tilde{E}_{t}\left(\pi_{t+1}^{w}\right)
$$




\section{A.2 Sticky Output Prices}

In period $t$, the firm will be able to change it's price with probability $1-\xi_{p}$.

The firm that can reset prices in period $t$ will choose $P_{t}(i)$ to maximize discounted future profits:

$$
\max _{P_{t}(i)} \tilde{E}_{t} \sum_{\tau=0}^{\infty} \beta^{\tau}\left(\xi_{p}\right)^{\tau} \lambda_{t+\tau}\left\{P_{t}(i) y_{t+\tau}(i)-M C_{t+\tau} y_{t+\tau}(i)\right\}
$$

where $M C_{t+\tau}$ is marginal cost of production in period $t+\tau$.

The firm's domestic demand is given in (??). Substitute this demand function into the maximization problem to express this problem as a function of one choice variable, $P_{t}(i)$ :

$$
\max _{P_{t}(i)} \tilde{E}_{t} \sum_{\tau=0}^{\infty} \beta^{\tau}\left(\xi_{p}\right)^{\tau} \lambda_{t+\tau}\left\{\begin{array}{c}
P_{t}(i)\left(\frac{P_{t}(i)}{P_{t+\tau}^{y}}\right)^{-\sigma} y_{t+\tau} \\
-M C_{t+\tau}\left(\frac{P_{t}(i)}{P_{t+\tau}^{y}}\right)^{-\sigma} y_{t+\tau}
\end{array}\right\}
$$

After some rearranging, the first order condition with respect to $P_{t}(i)$ is:

$$
P_{t}(i)=\frac{\sigma}{\sigma-1} \frac{\tilde{E}_{t} \sum_{\tau=0}^{\infty} \beta^{\tau}\left(\xi_{p}\right)^{\tau} \lambda_{t+\tau} M C_{t+\tau}\left(\frac{1}{P_{t+\tau}^{y}}\right)^{-\sigma} y_{t+\tau}}{\tilde{E}_{t} \sum_{\tau=0}^{\infty} \beta^{\tau}\left(\xi_{p}\right)^{\tau} \lambda_{t+\tau}\left(\frac{1}{P_{t+\tau}^{y}}\right)^{-\sigma} y_{t+\tau}}
$$

If prices are flexible, and thus $\xi_{p}=0$, then this expression reduces to:

$$
P_{t}^{d}(i)=\frac{\sigma}{\sigma-1} M C_{t}
$$

which says that the firm will set a price equal to a constant mark-up over marginal cost.

Write the domestic price set by the firm that can reset prices in period $t$ as $\bar{P}_{t}(i)$ to denote that it is an optimal price. Firms that can reset prices in period $t$ will all reset to the same level, so $\bar{P}_{t}(i)=\bar{P}_{t}$. Substitute this optimal price into the price index $P_{t}^{y}=\left(\int_{0}^{1}\left(P_{t}(i)\right)^{1-\sigma} d i\right)^{\frac{1}{1-\sigma}}$ and use the fact that in any period $1-\xi_{p}$ percent of firms will reoptimize prices to derive an expression for the core price index, $P_{t}^{y}$ : 


$$
P_{t}^{y}=\left(\xi_{p}\left(P_{t-1}^{y}\right)^{1-\sigma}+\left(1-\xi_{p}\right)\left(\bar{P}_{t}\right)^{1-\sigma}\right)^{\frac{1}{1-\sigma}}
$$

\section{A.2.1 Derivation of the NKPC for core inflation}

As presented in the text, the optimal wage in real terms is given by:

$$
p_{t}(i)=\frac{\sigma}{\sigma-1} \frac{\tilde{E}_{t} \sum_{\tau=0}^{\infty} \beta^{\tau}\left(\xi_{p}\right)^{\tau} \Lambda_{t+\tau} m c_{t+\tau}\left(\frac{1}{p_{t+\tau}^{y}}\right)^{-\sigma}\left(\Pi_{t, t+\tau}\right)^{\sigma} y_{t+\tau}}{\tilde{E}_{t} \sum_{\tau=0}^{\infty} \beta^{\tau}\left(\xi_{p}\right)^{\tau} \Lambda_{t+\tau}\left(\frac{1}{p_{t+\tau}^{y}}\right)^{-\sigma}\left(\Pi_{t, t+\tau}\right)^{\sigma-1} y_{t+\tau}}
$$

Furthermore, the expression for the evolution of the average wage in real terms is:

$$
p_{t}^{y}=\left(\xi_{p}\left(\frac{p_{t-1}^{y}}{\pi_{t}}\right)^{1-\sigma}+\left(1-\xi_{p}\right)\left(\tilde{p}_{t}\right)^{1-\sigma}\right)^{\frac{1}{1-\sigma}}
$$

Recall that $p_{t}(i)=\bar{p}_{t}$ for all firms that can change their price in period $t$. The linearized form of these two expressions is given by:

$$
\begin{aligned}
& \hat{p}_{t}^{*}=\sum_{\tau=0}^{\infty}\left(\beta \xi_{p}\right)^{\tau} \tilde{E}_{t}\left(\left(1-\beta \xi_{p}\right) \hat{c}_{t+\tau}+\beta \xi_{p} \pi_{t+\tau+1}\right) \\
& \hat{p}_{t}^{y}=\xi_{p}\left(\hat{p}_{t-1}^{y}-\pi_{t}\right)+\left(1-\xi_{p}\right) \hat{p}_{t}^{*}
\end{aligned}
$$

Furthermore note that the linearization of the core price evolution equation can be rewritten as $\hat{p}_{t}^{*}=\frac{1}{1-\xi_{p}}\left(\hat{p}_{t}^{y}-\xi_{p}\left(\hat{p}_{t-1}^{y}-\pi_{t}\right)\right)$ and $\tilde{E}_{t} \hat{p}_{t+1}^{*}=\frac{1}{1-\xi_{p}} \tilde{E}_{t}\left(\hat{p}_{t+1}^{y}-\xi_{p}\left(\hat{p}_{t}^{y}-\pi_{t+1}\right)\right)$. Then after a few substitutions and a lot of algebra, the New Keynesian Phillips Curve equation describing core inflation is given by:

$$
\pi_{t}^{y}=\frac{\left(1-\xi_{p}\right)\left(1-\beta \xi_{p}\right)}{\xi_{p}}\left(\hat{c}_{t}-\hat{p}_{t}^{y}\right)+\beta \tilde{E}_{t}\left(\pi_{t+1}^{y}\right)
$$


Table 1: Calibrated parameter values

\begin{tabular}{ccl}
\hline \hline Symbol & Value & Description \\
\hline$\beta$ & 0.99 & discount factor \\
$\alpha$ & .36 & capital share in production of value added \\
$\delta$ & 0.025 & capital depreciation rate \\
$\sigma$ & 10 & elasticity of substitution (eos) across varieties from different firms \\
$\theta$ & 21 & eos between labor from different households \\
$\xi_{p}$ & 0.75 & probability that a firm cannot reset prices \\
$\xi_{w}$ & 0.75 & probability that a household cannot reset wages \\
$\theta_{p}$ & 1.5 & coefficient on inflation in the Taylor rule \\
$\theta_{y}$ & .5 & coefficient on the output gap in the Taylor rule \\
\hline \hline
\end{tabular}




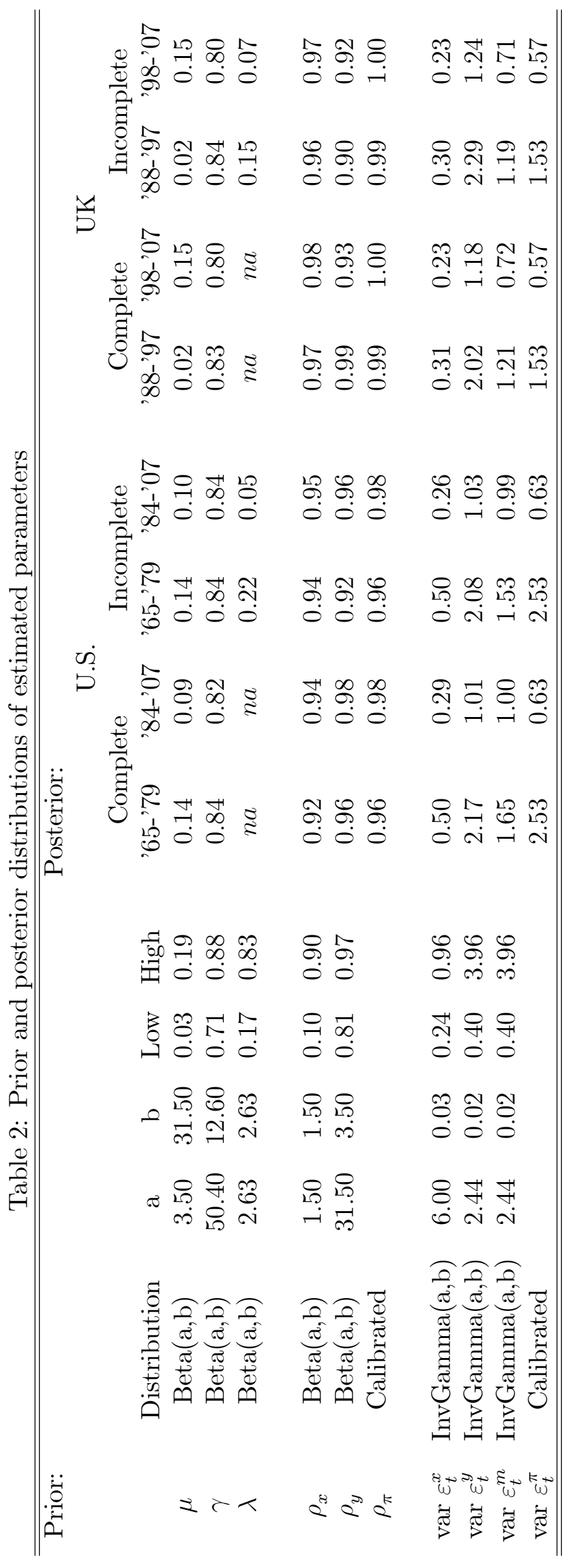


Table 3: Prior and posterior distributions of estimated parameters

\begin{tabular}{|c|c|c|c|c|c|c|c|}
\hline \multicolumn{8}{|c|}{ Posterior: } \\
\hline \multicolumn{4}{|c|}{ Canada } & \multicolumn{4}{|c|}{ Norway } \\
\hline \multicolumn{2}{|c|}{ Complete } & \multicolumn{2}{|c|}{ Incomplete } & \multicolumn{2}{|c|}{ Complete } & \multicolumn{2}{|c|}{ Incomplete } \\
\hline '74-'90 & '91-'07 & '74-'90 & '91-'07 & '94-'00 & '01-'07 & '94-'00 & '01-07' \\
\hline 0.23 & 0.11 & 0.27 & 0.10 & 0.37 & 0.03 & 0.40 & 0.03 \\
\hline 0.82 & 0.82 & 0.80 & 0.79 & 0.71 & 0.81 & 0.68 & 0.81 \\
\hline$n a$ & $n a$ & 0.30 & 0.01 & $n a$ & $n a$ & 0.25 & 0.15 \\
\hline 0.96 & 0.95 & 0.96 & 0.93 & 0.83 & 0.90 & 0.87 & 0.90 \\
\hline 0.92 & 0.89 & 0.64 & 0.69 & 0.85 & 0.84 & 0.49 & 0.78 \\
\hline 0.98 & 0.99 & 0.98 & 0.99 & 1.00 & 0.99 & 1.00 & 0.99 \\
\hline 0.66 & 0.33 & 0.76 & 0.39 & 0.99 & 0.25 & 1.21 & 0.24 \\
\hline 3.28 & 1.88 & 4.17 & 2.36 & 2.90 & 2.89 & 3.89 & 3.09 \\
\hline 1.78 & 0.99 & 1.78 & 1.00 & 1.41 & 1.12 & 1.24 & 1.07 \\
\hline 2.31 & 0.40 & 2.31 & 0.40 & 2.08 & 0.29 & 2.08 & 0.29 \\
\hline \multicolumn{4}{|c|}{ Switzerland } & \multicolumn{4}{|c|}{ Sweden } \\
\hline \multicolumn{2}{|c|}{ Complete } & \multicolumn{2}{|c|}{ Incomplete } & \multicolumn{2}{|c|}{ Complete } & \multicolumn{2}{|c|}{ Incomplete } \\
\hline '92-'99 & '00-'07 & '92-'99 & '00-'07 & '78-'92 & '93-'07 & '78-'92 & '93-'07 \\
\hline 0.17 & 0.24 & 0.18 & 0.17 & 0.43 & 0.42 & 0.43 & 0.32 \\
\hline 0.83 & 0.79 & 0.82 & 0.84 & 0.65 & 0.67 & 0.65 & 0.62 \\
\hline na & na & 0.17 & 0.07 & $n a$ & $n a$ & 0.22 & 0.06 \\
\hline 0.94 & 0.89 & 0.95 & 0.90 & 0.96 & 0.97 & 0.96 & 0.96 \\
\hline 0.91 & 0.43 & 0.68 & 0.63 & 0.46 & 0.98 & 0.36 & 0.91 \\
\hline 0.99 & 0.98 & 0.99 & 0.98 & 0.99 & 1.00 & 0.99 & 1.00 \\
\hline 0.33 & 0.44 & 0.33 & 0.31 & 4.14 & 3.56 & 4.28 & 3.50 \\
\hline 1.62 & 2.38 & 2.18 & 2.22 & 8.82 & 2.71 & 9.87 & 2.77 \\
\hline 1.33 & 1.06 & 1.22 & 0.98 & 3.68 & 2.88 & 3.50 & 2.81 \\
\hline 1.30 & 0.13 & 1.30 & 0.13 & 1.95 & 0.83 & 1.95 & 0.83 \\
\hline
\end{tabular}


Table 4: The volatility and persistence of inflation and GDP from simulations of the model.

\begin{tabular}{|c|c|c|c|c|c|c|c|}
\hline \multirow{2}{*}{\multicolumn{2}{|c|}{ U.S.: }} & \multicolumn{2}{|c|}{ Data } & \multicolumn{2}{|c|}{ Complete } & \multicolumn{2}{|c|}{ Incomplete } \\
\hline & & '65-'79 & '84-'07 & '65-'79 & '84-'07 & '65-'79 & '84-'07 \\
\hline St. Dev. & $\pi$ & 0.82 & 0.52 & 1.18 & 0.72 & 1.69 & 0.83 \\
\hline \multirow{3}{*}{$\begin{array}{l}\text { St. Dev. } \\
\text { rel. to } \pi\end{array}$} & $\pi^{y}$ & 0.88 & 0.56 & 0.61 & 0.52 & 0.87 & 0.70 \\
\hline & $\pi^{x}$ & 2.77 & 4.66 & 4.15 & 4.48 & 3.02 & 3.87 \\
\hline & $G D P$ & 1.99 & 1.75 & 1.06 & 0.96 & 0.90 & 0.91 \\
\hline \multirow[t]{4}{*}{ Autocorr. } & $\pi$ & 0.79 & -0.07 & 0.16 & 0.09 & 0.61 & 0.32 \\
\hline & $\pi^{y}$ & 0.80 & 0.71 & 0.80 & 0.78 & 0.95 & 0.91 \\
\hline & $\pi^{x}$ & 0.37 & -0.14 & 0.01 & 0.03 & -0.01 & 0.02 \\
\hline & $G D P$ & 0.93 & 0.94 & 0.83 & 0.87 & 0.89 & 0.89 \\
\hline \multirow{2}{*}{\multicolumn{2}{|c|}{ UK: }} & \multicolumn{2}{|c|}{ Data } & \multicolumn{2}{|c|}{ Complete } & \multicolumn{2}{|c|}{ Incomplete } \\
\hline & & '88-'97 & '98-'07 & '88-'97 & '98-'07 & '88-'97 & '98-'07 \\
\hline St. Dev. & $\pi$ & 0.65 & 0.32 & 1.17 & 0.55 & 1.47 & 0.67 \\
\hline \multirow{3}{*}{$\begin{array}{l}\text { St. Dev. } \\
\text { rel. to } \pi\end{array}$} & $\pi^{y}$ & 1.24 & 0.68 & 0.76 & 0.59 & 0.87 & 0.75 \\
\hline & $\pi^{x}$ & 4.66 & 3.40 & 4.74 & 4.32 & 3.76 & 3.69 \\
\hline & $G D P$ & 2.36 & 2.66 & 1.12 & 1.03 & 0.80 & 0.98 \\
\hline \multirow{4}{*}{ Autocorr. } & $\pi$ & 0.50 & -0.11 & 0.25 & 0.08 & 0.49 & 0.36 \\
\hline & $\pi^{y}$ & 0.75 & 0.15 & 0.81 & 0.70 & 0.91 & 0.87 \\
\hline & $\pi^{x}$ & 0.11 & -0.17 & 0.24 & -0.01 & 0.11 & -0.02 \\
\hline & $G D P$ & 0.97 & 0.97 & 0.96 & 0.84 & 0.95 & 0.87 \\
\hline \multirow[t]{2}{*}{ Canada: } & & \multicolumn{2}{|c|}{ Data } & \multicolumn{2}{|c|}{ Complete } & \multicolumn{2}{|c|}{ Incomplete } \\
\hline & & '74-'90 & '91-'07 & '74-'90 & '91-'07 & '74-'90 & '91-'07 \\
\hline St. Dev. & $\pi$ & 0.81 & 0.48 & 1.21 & 0.69 & 1.74 & 0.70 \\
\hline \multirow{3}{*}{$\begin{array}{l}\text { St. Dev. } \\
\text { rel. to } \pi\end{array}$} & $\pi^{y}$ & 0.93 & 0.63 & 0.69 & 0.62 & 0.89 & 0.58 \\
\hline & $\pi^{x}$ & 2.23 & 3.99 & 4.03 & 4.71 & 2.97 & 4.79 \\
\hline & $G D P$ & 2.36 & 2.11 & 1.28 & 1.02 & 0.97 & 0.88 \\
\hline \multirow[t]{4}{*}{ Autocorr. } & $\pi$ & 0.83 & -0.18 & 0.20 & 0.07 & 0.63 & 0.04 \\
\hline & $\pi^{y}$ & 0.61 & 0.12 & 0.74 & 0.65 & 0.92 & 0.57 \\
\hline & $\pi^{x}$ & 0.41 & -0.37 & -0.02 & 0.07 & -0.12 & 0.02 \\
\hline & $G D P$ & 0.92 & 0.94 & 0.79 & 0.83 & 0.77 & 0.78 \\
\hline
\end{tabular}


Table 5: The volatility and persistence of inflation and GDP from simulations of the model.

\begin{tabular}{|c|c|c|c|c|c|c|c|}
\hline \multirow[t]{2}{*}{ Norway: } & & \multicolumn{2}{|c|}{ Data } & \multicolumn{2}{|c|}{ Complete } & \multicolumn{2}{|c|}{ Incomplete } \\
\hline & & '94-'00 & '01-'07 & '94-'00 & '01-'07 & '94-'00 & '01-'07 \\
\hline St. Dev. & $\pi$ & 0.64 & 0.74 & 0.78 & 0.77 & 0.93 & 0.91 \\
\hline \multirow{3}{*}{$\begin{array}{l}\text { St. Dev. } \\
\text { rel. to } \pi\end{array}$} & $\pi^{y}$ & 1.04 & 0.62 & 0.80 & 0.81 & 0.94 & 0.89 \\
\hline & $\pi^{x}$ & 1.66 & 6.03 & 4.74 & 5.54 & 3.82 & 4.74 \\
\hline & $G D P$ & 1.73 & 0.72 & 1.72 & 0.68 & 1.27 & 0.62 \\
\hline \multirow[t]{4}{*}{ Autocorr. } & $\pi$ & 0.64 & -0.03 & 0.32 & 0.03 & 0.71 & 0.28 \\
\hline & $\pi^{y}$ & 0.71 & 0.10 & 0.74 & 0.60 & 0.86 & 0.75 \\
\hline & $\pi^{x}$ & 0.14 & -0.07 & -0.13 & 0.16 & -0.18 & 0.09 \\
\hline & $G D P$ & 0.83 & 0.88 & 0.63 & 0.86 & 0.52 & 0.88 \\
\hline \multirow[t]{2}{*}{ Switzerland: } & & \multicolumn{2}{|c|}{ Data } & \multicolumn{2}{|c|}{ Complete } & \multicolumn{2}{|c|}{ Incomplete } \\
\hline & & '92-'99 & '00-'07 & '92-'99 & '00-'07 & '92-'99 & '00-'07 \\
\hline St. Dev. & $\pi$ & 0.65 & 0.35 & 0.88 & 0.60 & 0.99 & 0.69 \\
\hline \multirow{3}{*}{$\begin{array}{l}\text { St. Dev. } \\
\text { rel. to } \pi\end{array}$} & $\pi^{y}$ & 0.80 & 0.62 & 0.54 & 0.45 & 0.76 & 0.64 \\
\hline & $\pi^{x}$ & 2.77 & 3.89 & 4.19 & 4.58 & 3.63 & 4.18 \\
\hline & $G D P$ & 1.58 & 3.44 & 0.93 & 1.04 & 0.84 & 0.91 \\
\hline \multirow[t]{4}{*}{ Autocorr. } & $\pi$ & 0.48 & -0.33 & 0.07 & -0.08 & 0.36 & 0.14 \\
\hline & $\pi^{y}$ & 0.78 & -0.47 & 0.75 & 0.32 & 0.89 & 0.72 \\
\hline & $\pi^{x}$ & 0.01 & -0.40 & -0.06 & -0.12 & -0.11 & -0.05 \\
\hline & $G D P$ & 0.93 & 0.95 & 0.77 & 0.59 & 0.78 & 0.72 \\
\hline \multirow[t]{2}{*}{ Sweden: } & & \multicolumn{2}{|c|}{ Data } & \multicolumn{2}{|c|}{ Complete } & \multicolumn{2}{|c|}{ Incomplete } \\
\hline & & '78-'92 & '93-'07 & '78-'92 & '93-'07 & '78-'92 & $' 93-' 07$ \\
\hline St. Dev. & $\pi$ & 1.11 & 0.51 & 1.26 & 1.12 & 2.12 & 1.69 \\
\hline St. Dev. & $\pi^{y}$ & 0.89 & 0.98 & 0.80 & 0.65 & 0.96 & 0.83 \\
\hline \multirow[t]{2}{*}{ rel. to $\pi$} & $\pi^{x}$ & 2.32 & 4.07 & 7.87 & 6.88 & 4.73 & 5.10 \\
\hline & $G D P$ & 2.59 & 1.55 & 2.38 & 2.44 & 1.55 & 1.51 \\
\hline \multirow[t]{4}{*}{ Autocorr. } & $\pi$ & 0.24 & 0.21 & 0.15 & 0.19 & 0.75 & 0.56 \\
\hline & $\pi^{y}$ & 0.14 & 0.54 & 0.43 & 0.79 & 0.86 & 0.94 \\
\hline & $\pi^{x}$ & 0.09 & -0.09 & -0.23 & -0.15 & -0.23 & -0.13 \\
\hline & $G D P$ & 0.75 & 0.84 & 0.29 & 0.57 & 0.41 & 0.61 \\
\hline
\end{tabular}



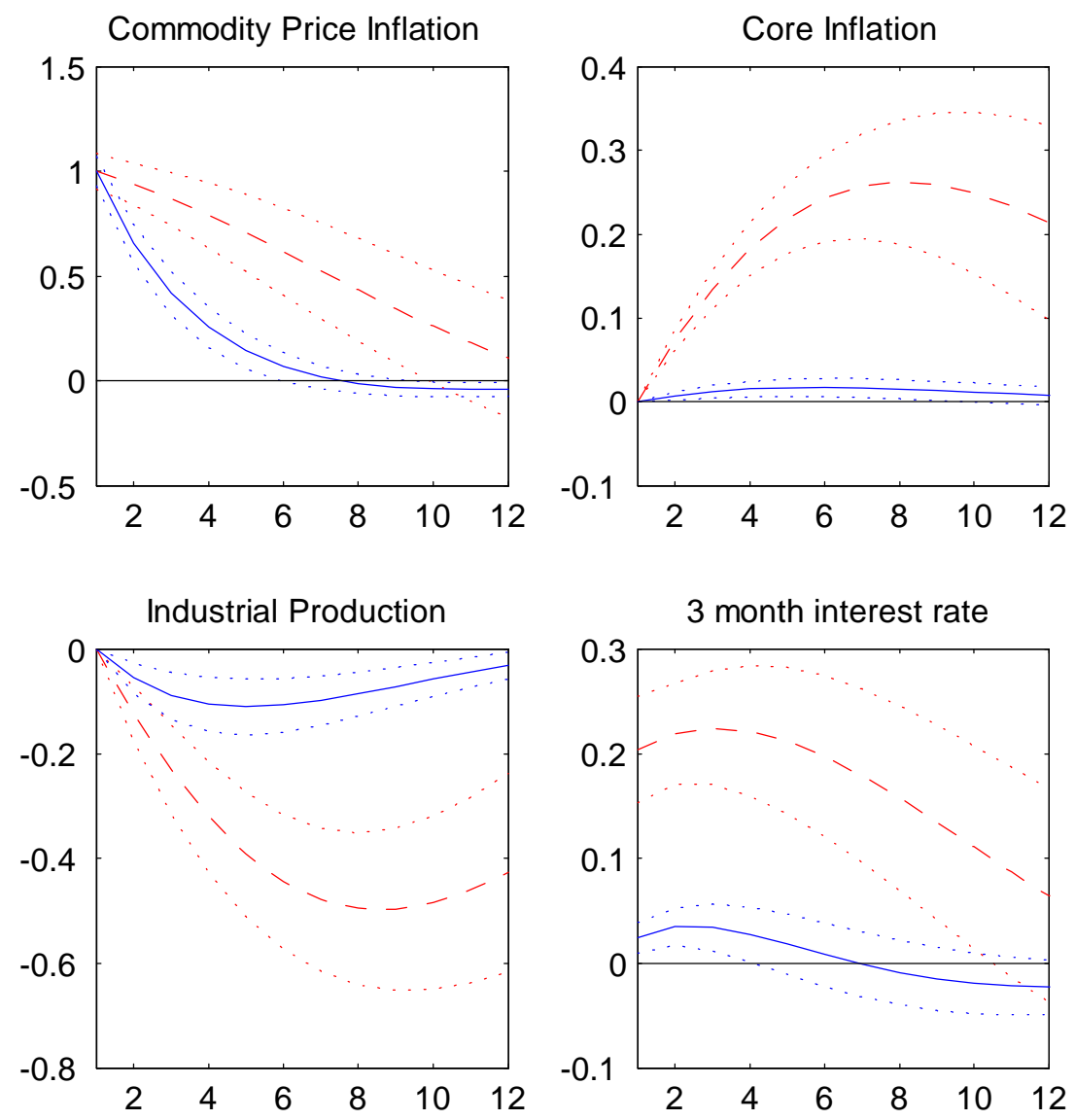

Figure 1: Responses to a shock to commodity price inflation. Taken from U.S. data, dashed line is the 1965-1979 time period and the solid line represents 1984-2007. 

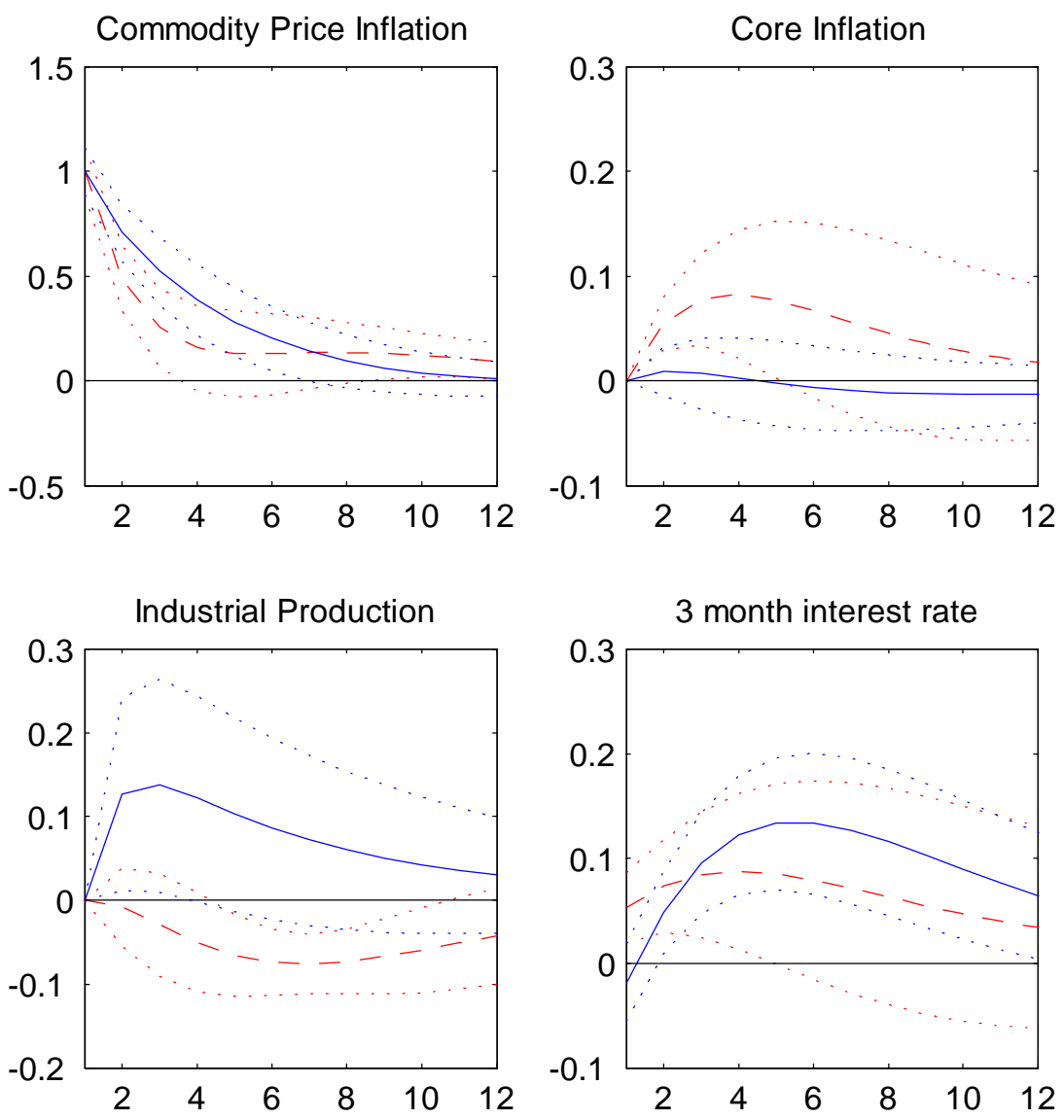

Figure 2: Responses to a shock to commodity price inflation. Taken from UK data, dashed line is the 1988-1997 time period and the solid line represents 1998-2007. 

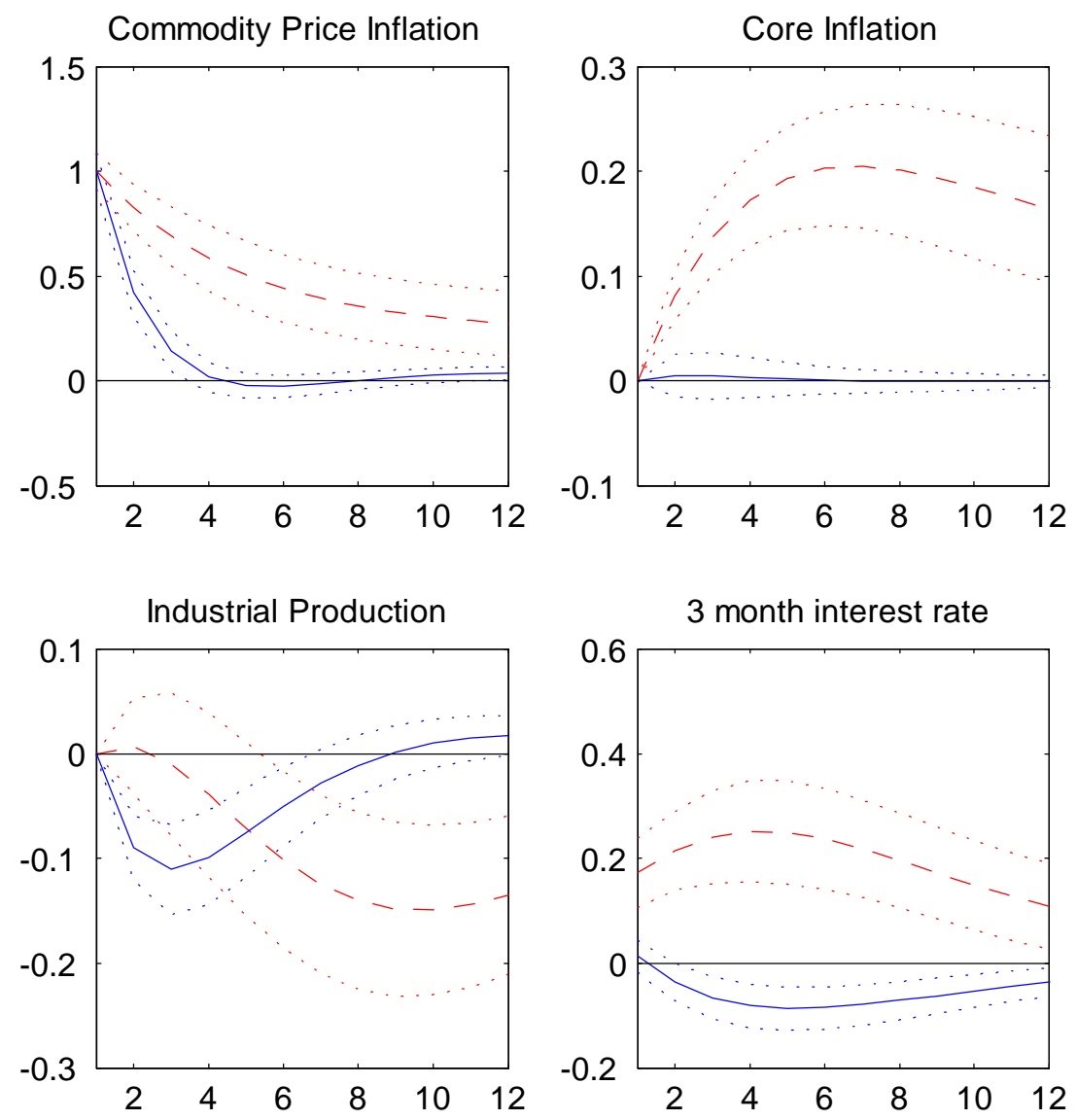

Figure 3: Responses to a shock to commodity price inflation. Taken from Canadian data, dashed line is the 1974-1990 time period and the solid line represents 1991-2007. 

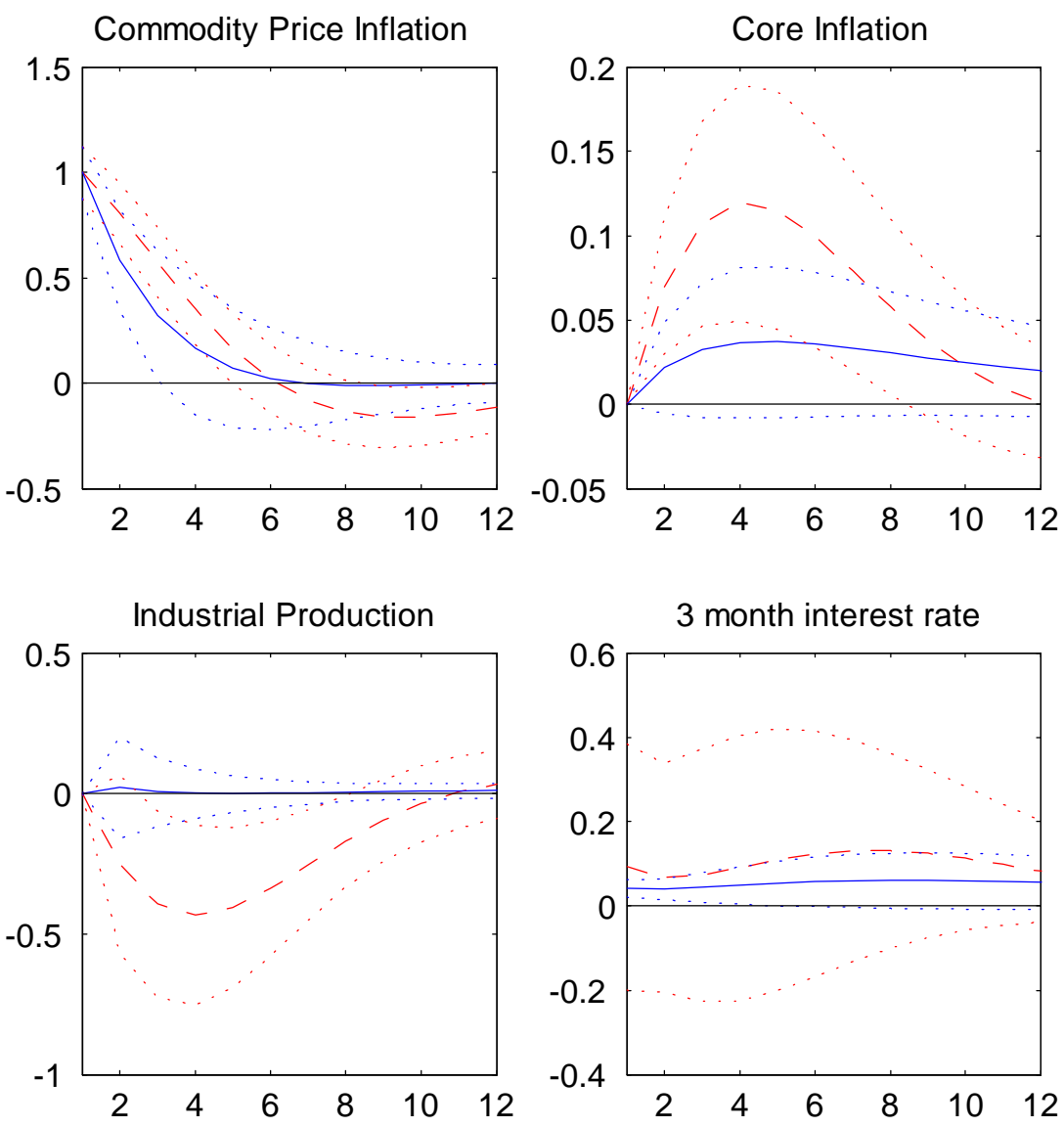

Figure 4: Responses to a shock to commodity price inflation. Taken from Norwegian data, dashed line is the 1994-2000 time period and the solid line represents 2001-2007. 

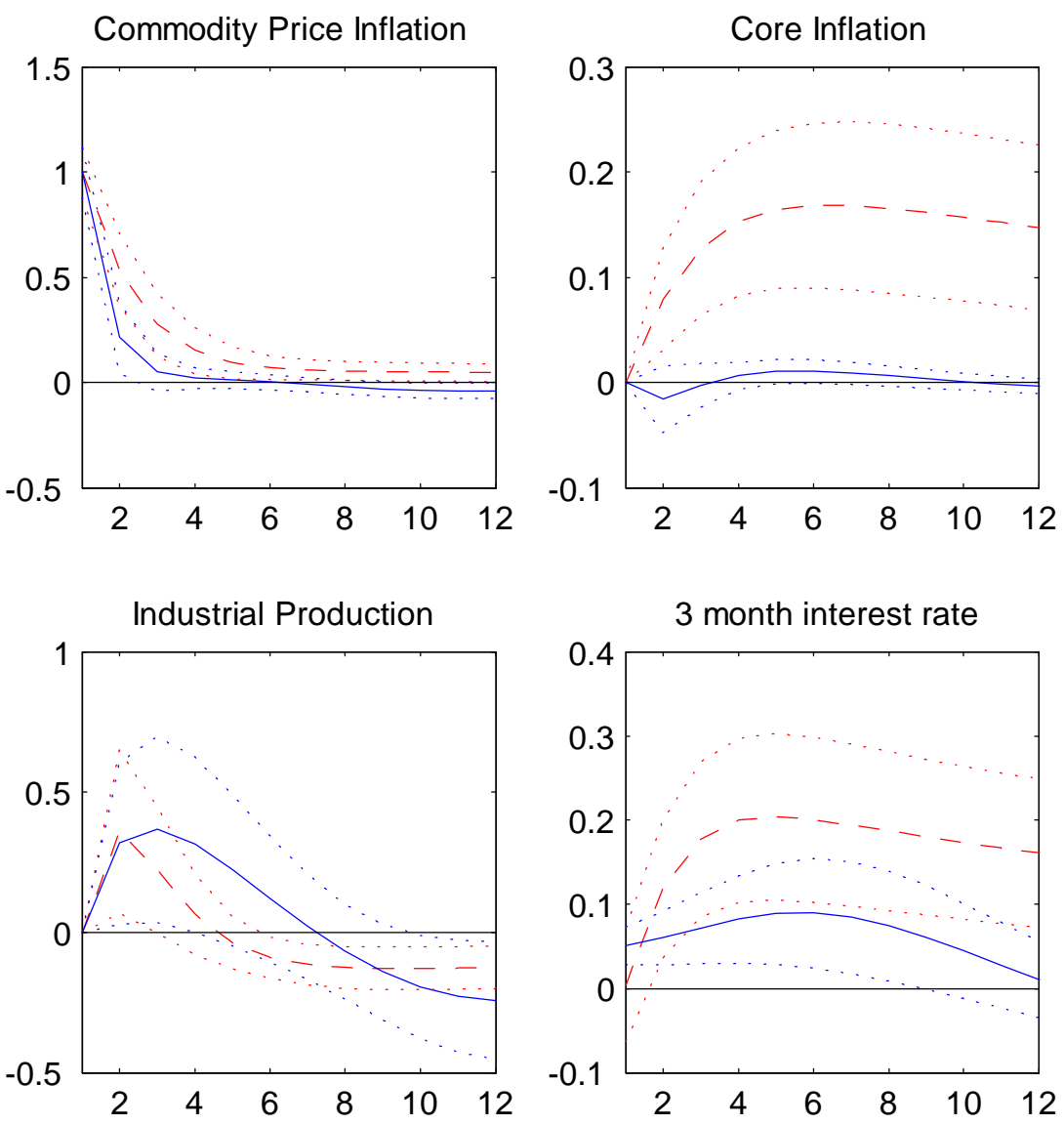

Figure 5: Responses to a shock to commodity price inflation. Taken from Swiss data, dashed line is the 1992-1999 time period and the solid line represents 2000-2007. 

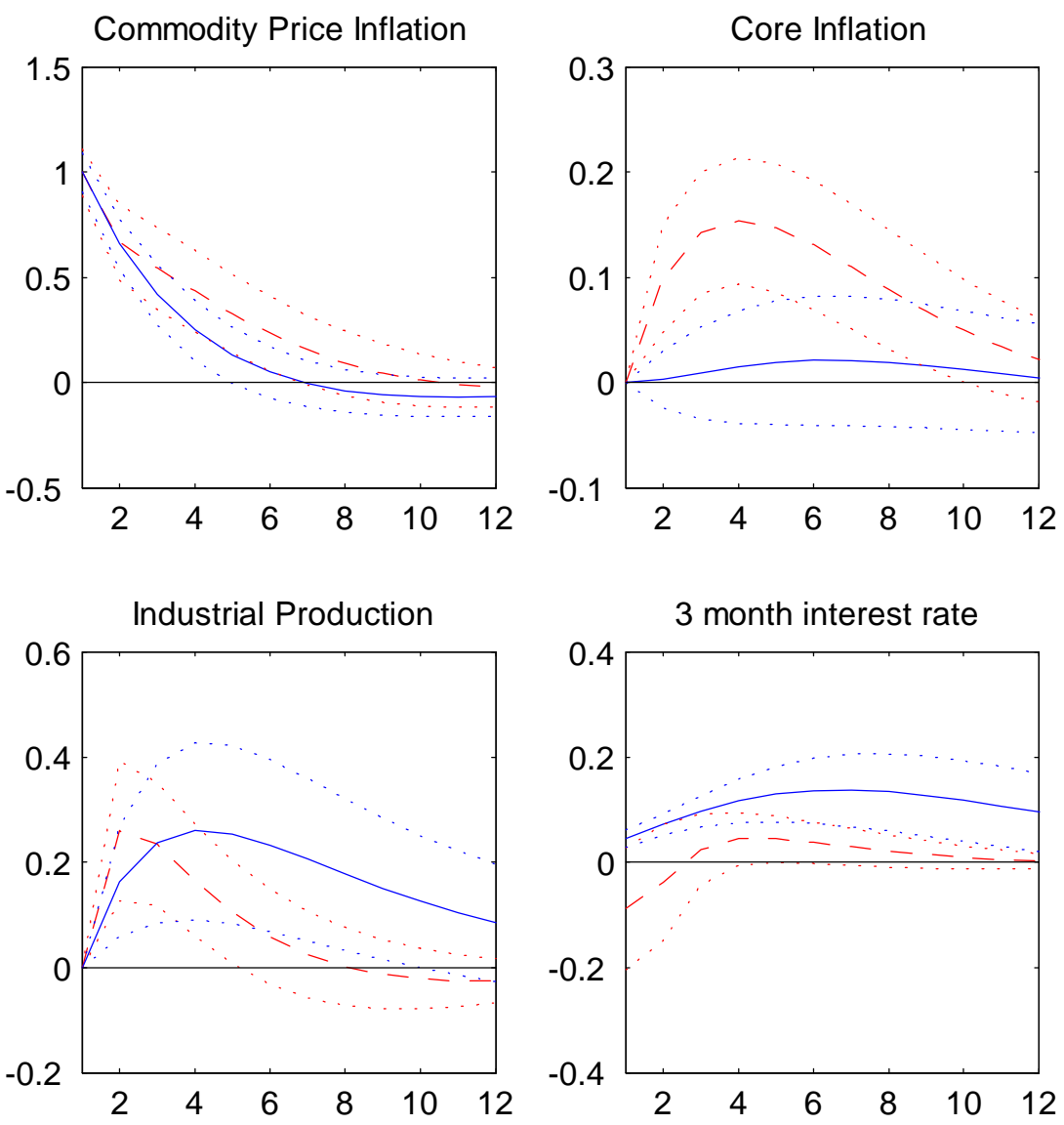

Figure 6: Responses to a shock to commodity price inflation. Taken from Swedish data, dashed line is the 1978-1992 time period and the solid line represents 1993-2007. 

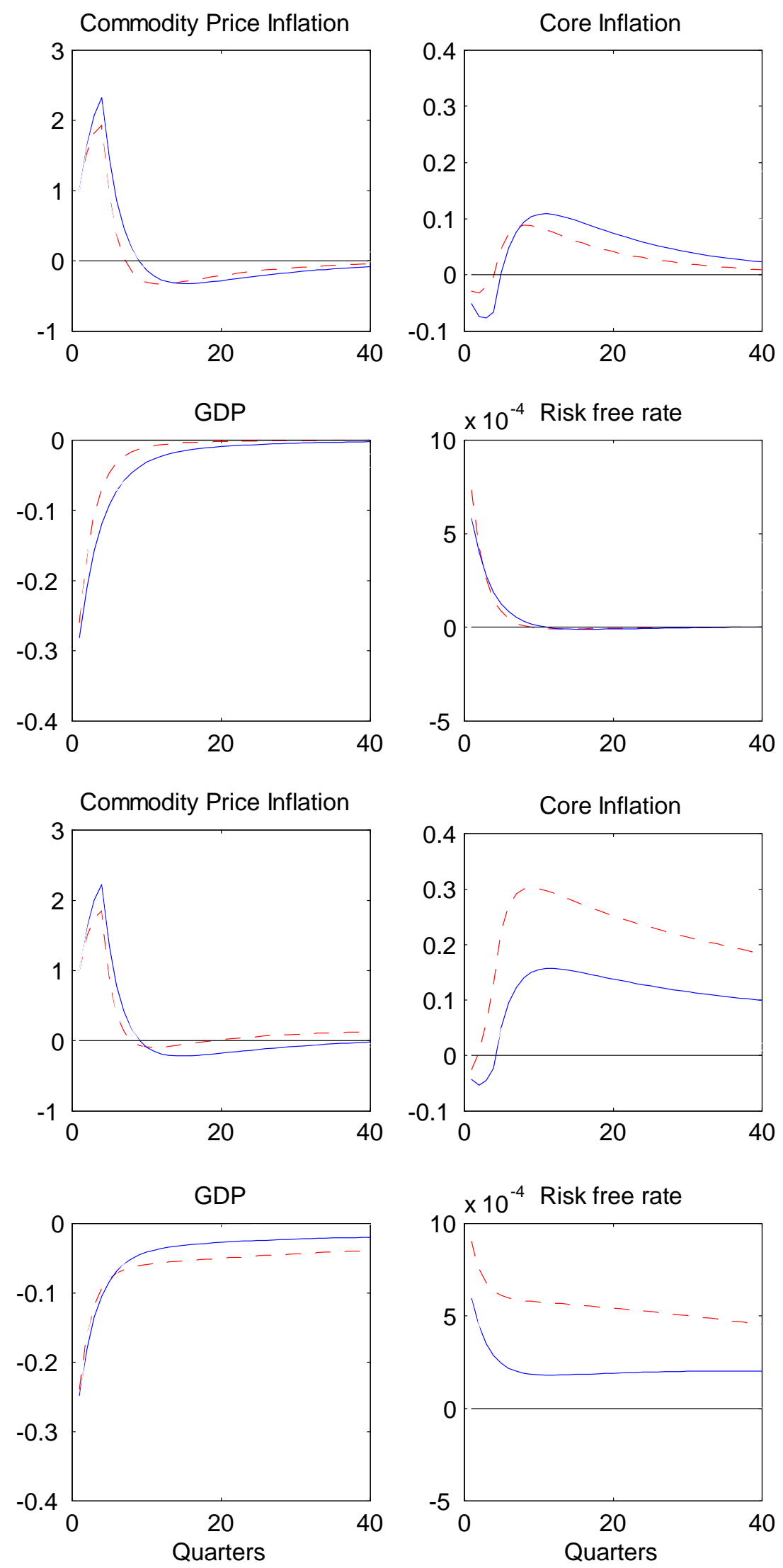

Figure 7: Impulse responses from simulations of the model parameterized with U.S. data. The top half of the figure presents responses 4.9 the model under complete information, the bottom half of the figure presents responses under incomplete information. The red dashed line is the earlier period and the blue solid line is the later period. 

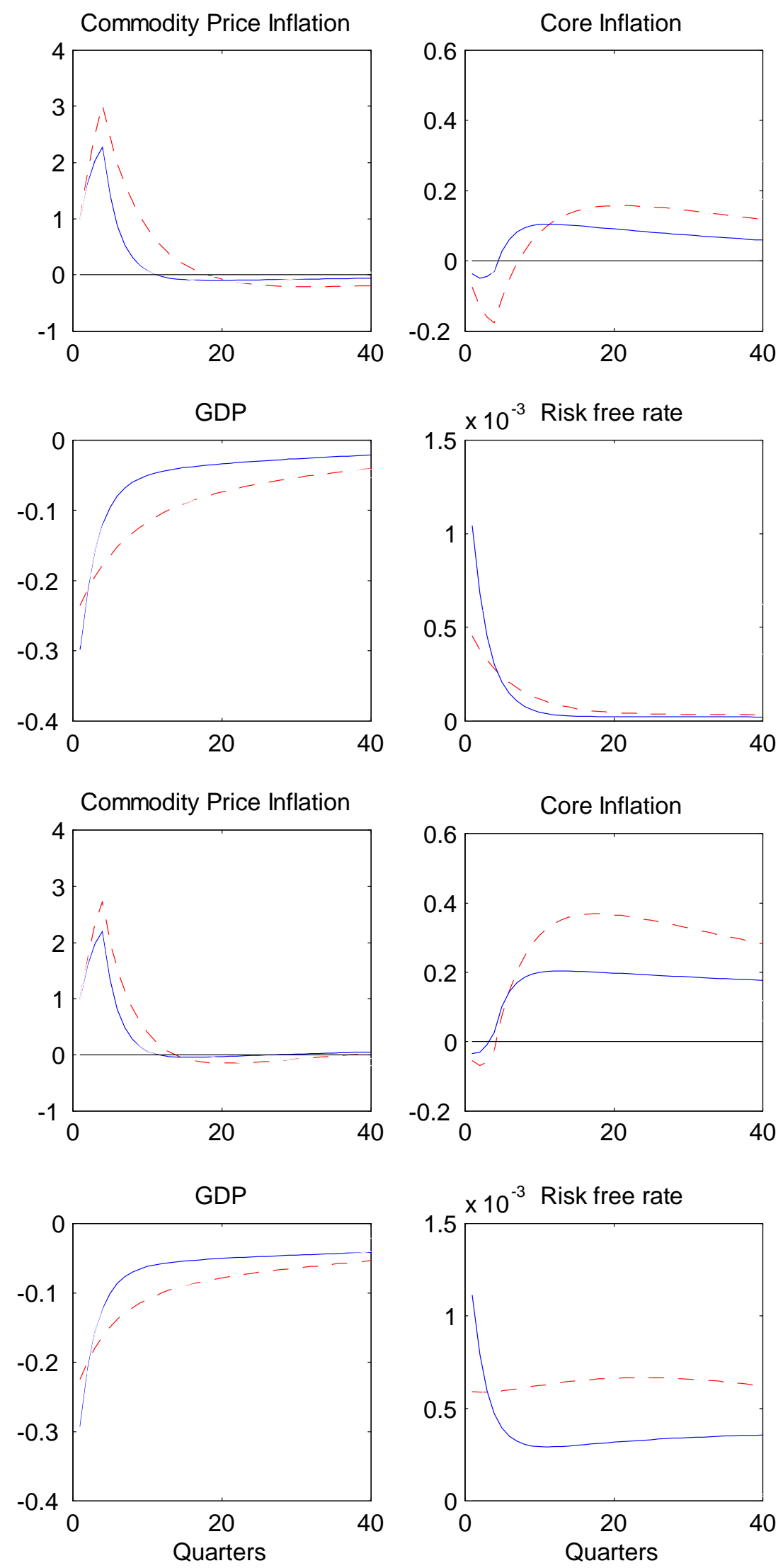

Figure 8: Impulse responses from simulations of the model parameterized with UK data. The top half of the figure presents responses 5 in the model under complete information, the bottom half of the figure presents responses under incomplete information. The red dashed line is the earlier period and the blue solid line is the later period. 

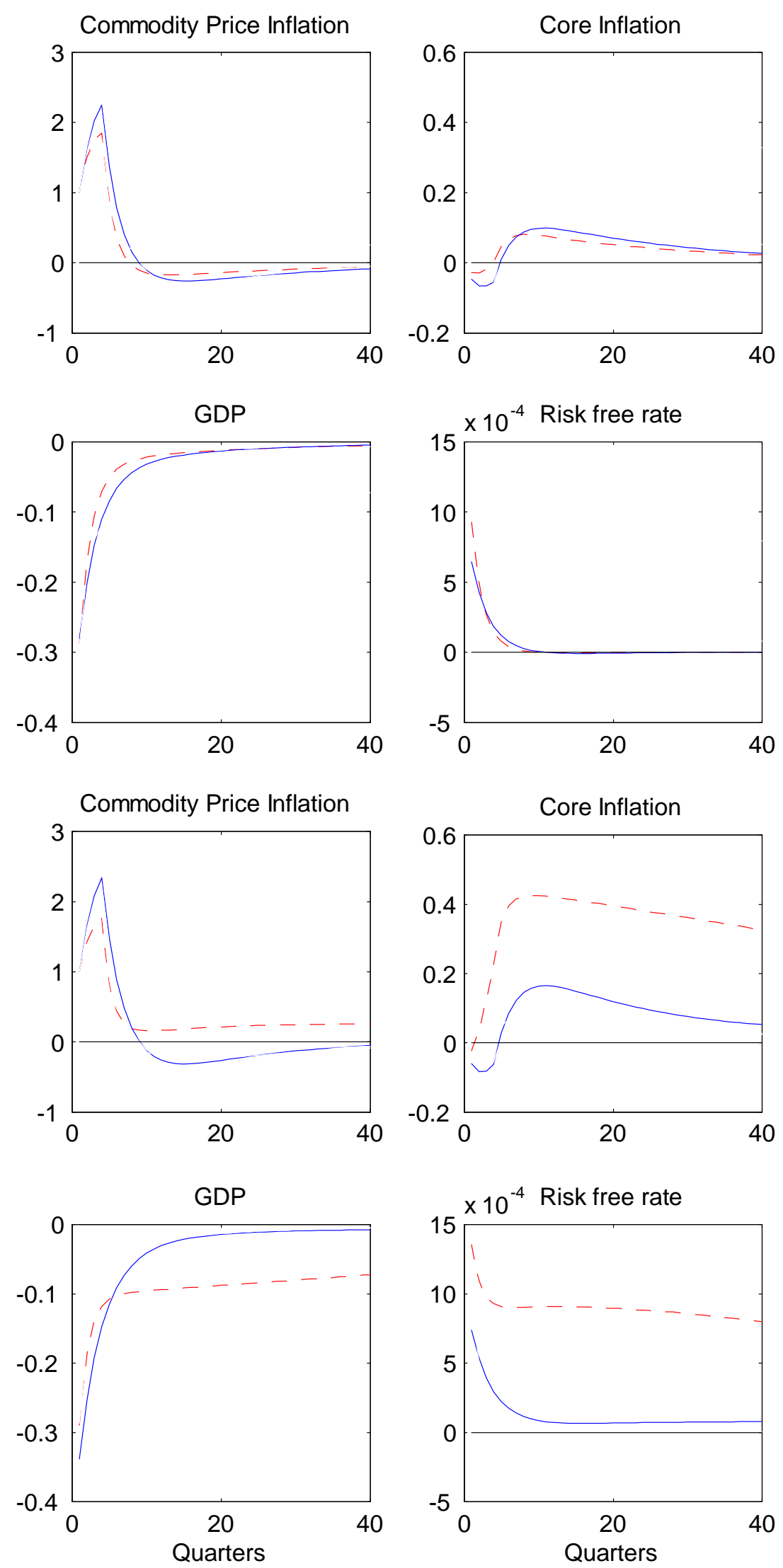

Figure 9: Impulse responses from simulations of the model parameterized with Canadian data. The top half of the figure presents resportses in the model under complete information, the bottom half of the figure presents responses under incomplete information. The red dashed line is the earlier period and the blue solid line is the later period. 

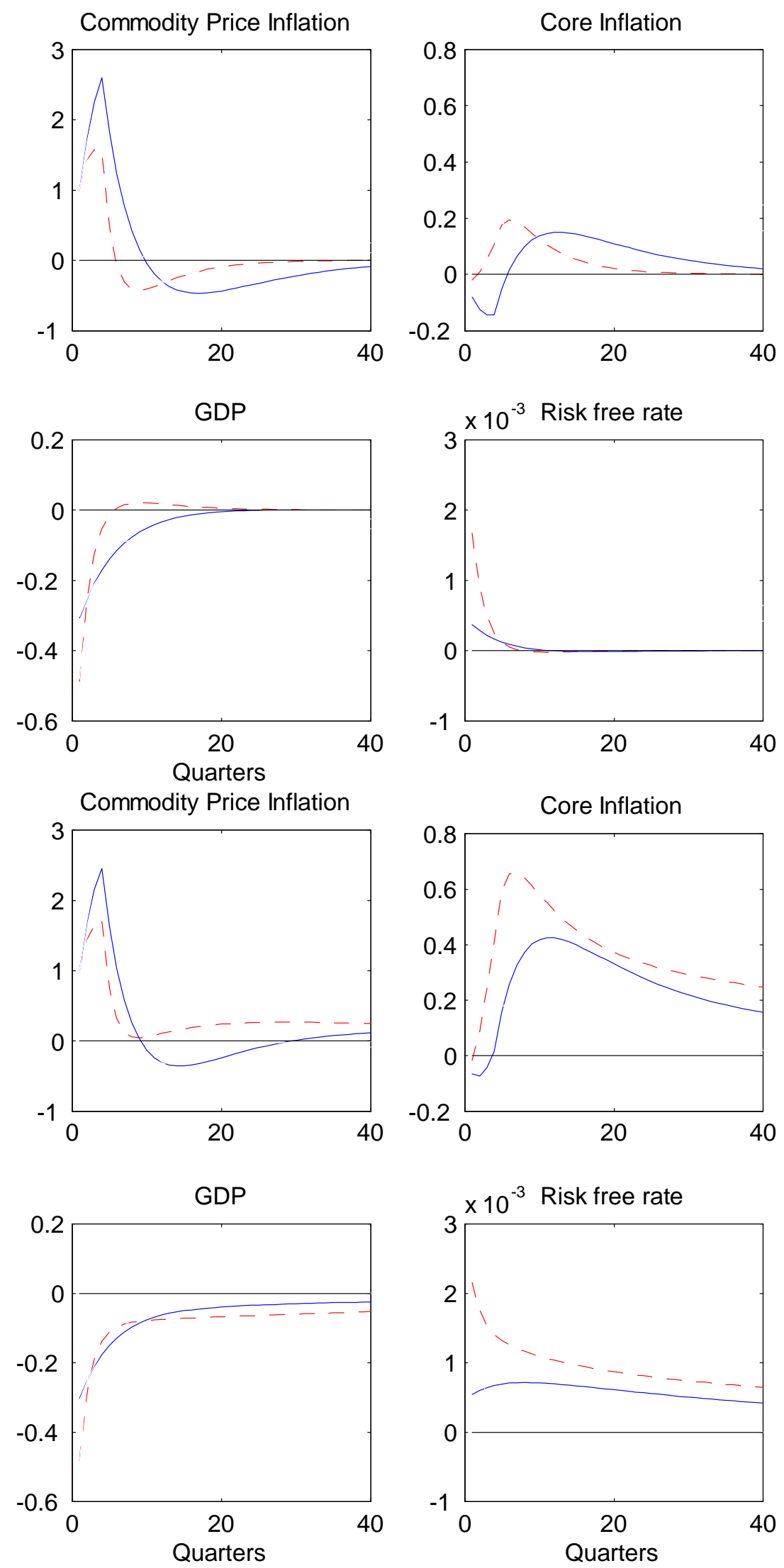

Figure 10: Impulse responses from simulations of the model parameterized with Norwegian data. The top half of the figure presents resp84ises in the model under complete information, the bottom half of the figure presents responses under incomplete information. The red dashed line is the earlier period and the blue solid line is the later period. 

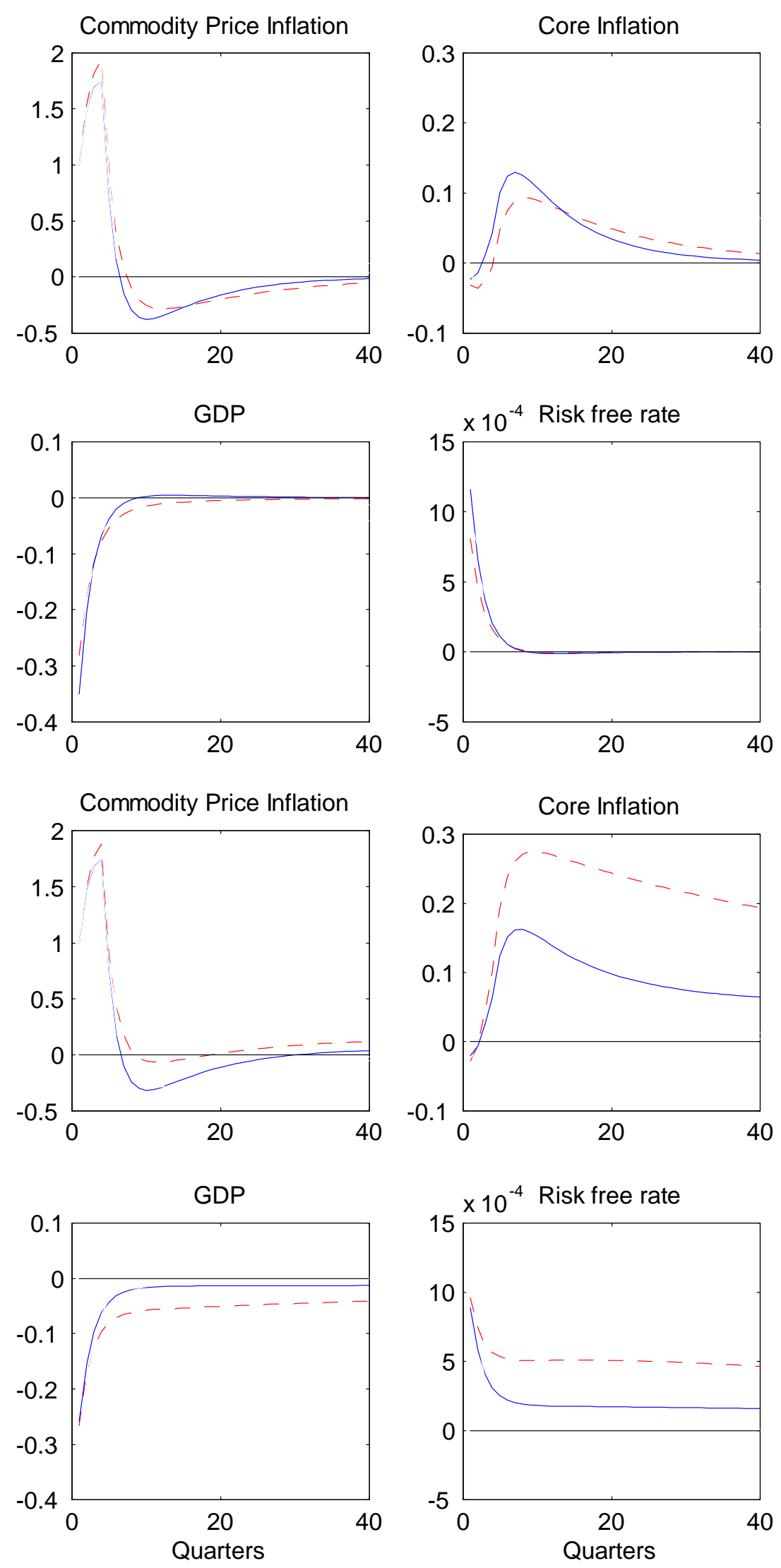

Figure 11: Impulse responses from simulations of the model parameterized with Swiss data. The top half of the figure presents responses 5 is the model under complete information, the bottom half of the figure presents responses under incomplete information. The red dashed line is the earlier period and the blue solid line is the later period. 

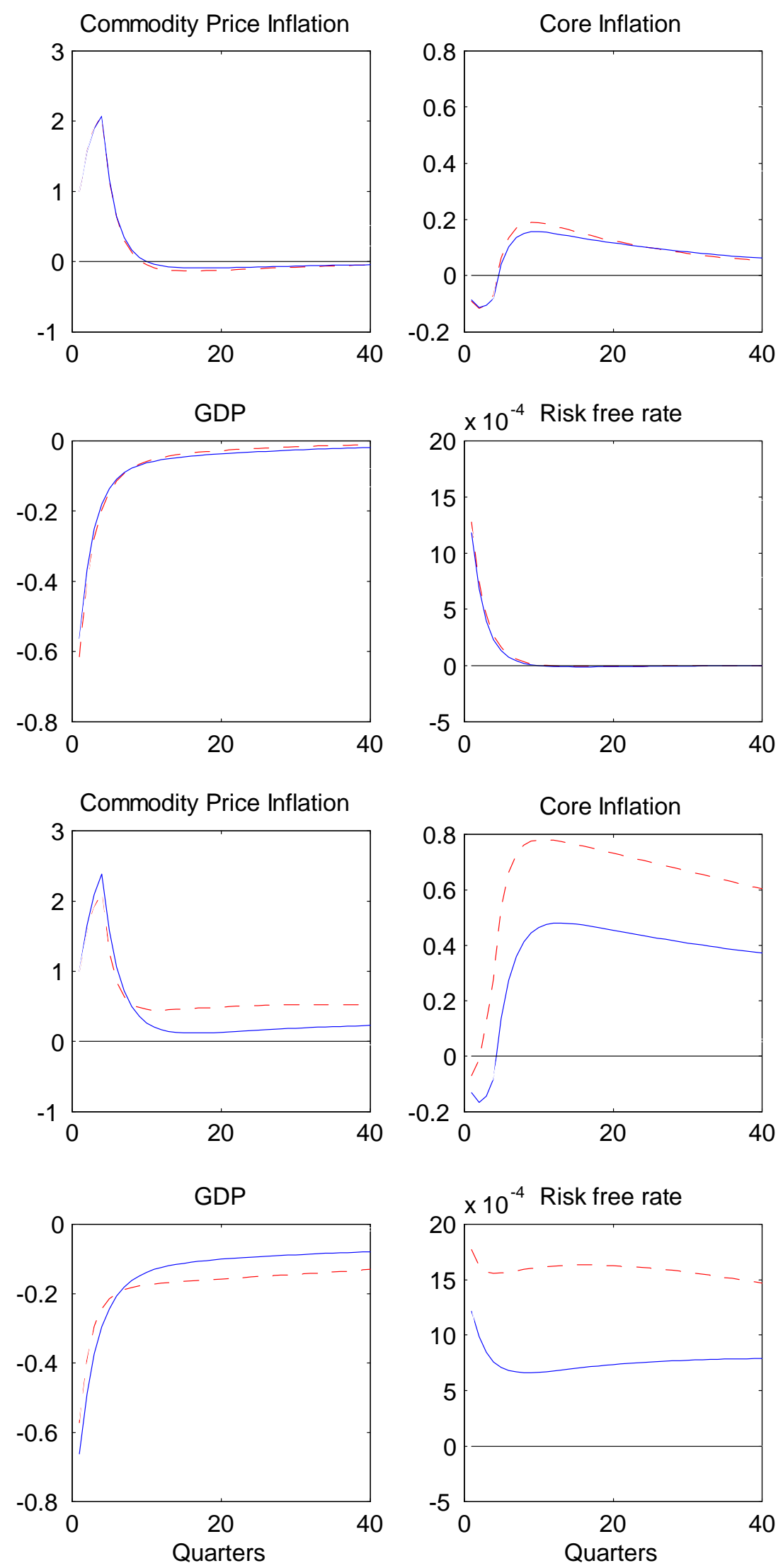

Figure 12: Impulse responses from simulations of the model parameterized with Swedish data. The top half of the figure presents respơftses in the model under complete information, the bottom half of the figure presents responses under incomplete information. The red dashed line is the earlier period and the blue solid line is the later period. 